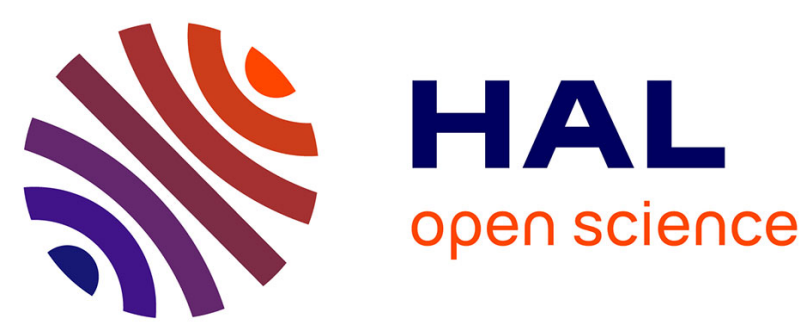

\title{
Zooplankton abundance and community structure driven by tidal currents in a Mediterranean coastal lagoon (Boughrara, Tunisia, SW Mediterranean Sea)
}

Nouha Makhlouf Belkahia, Marc Pagano, Cristele Chevalier, Jean-Luc Devenon, Mohamed Néjib Daly Yahia

\section{To cite this version:}

Nouha Makhlouf Belkahia, Marc Pagano, Cristele Chevalier, Jean-Luc Devenon, Mohamed Néjib Daly Yahia. Zooplankton abundance and community structure driven by tidal currents in a Mediterranean coastal lagoon (Boughrara, Tunisia, SW Mediterranean Sea). Estuarine, Coastal and Shelf Science, 2021, 250, pp.107101. 10.1016/j.ecss.2020.107101 . hal-03151803

\section{HAL Id: hal-03151803 \\ https://hal-amu.archives-ouvertes.fr/hal-03151803}

Submitted on 25 Feb 2021

HAL is a multi-disciplinary open access archive for the deposit and dissemination of scientific research documents, whether they are published or not. The documents may come from teaching and research institutions in France or abroad, or from public or private research centers.
L'archive ouverte pluridisciplinaire HAL, est destinée au dépôt et à la diffusion de documents scientifiques de niveau recherche, publiés ou non, émanant des établissements d'enseignement et de recherche français ou étrangers, des laboratoires publics ou privés.

\section{(1) (1) $\$$}

Distributed under a Creative Commons Attribution - NonCommercial - NoDerivatives 44.0 
Zooplankton abundance and community structure driven by tidal currents in a Mediterranean coastal lagoon (Boughrara, Tunisia, SW Mediterranean Sea)

Nouha Makhlouf Belkahia ${ }^{1,2}$, Marc Pagano ${ }^{3}$, Cristèle Chevalier ${ }^{3}$ Jean Luc Devenon ${ }^{3}$ and Mohamed Néjib Daly Yahia ${ }^{4}$

${ }^{1}$ Faculté des Sciences de Bizerte, Zarzouna 7021, Tunisia.

${ }^{2}$ Université de Tunis El Manar, Faculté des Sciences de Tunis, LR18ES41 Sciences de l'Environnement, Biologie et physiologie des Organismes Aquatiques, Tunis, Tunisia.

${ }^{3}$ Aix Marseille Université, Université de Toulon, CNRS, IRD, MIO UM 110, 13288, Marseille, France.

${ }^{4}$ Qatar University, College of Arts and Sciences, Department of Biological and Environmental Sciences, 2713 Doha, Qatar.

\begin{abstract}
.
Lagoons and coastal marine zones are very productive and useful ecosystems, but they are threatened by the effects of global change and anthropogenic pressures. These effects have a negative impact on the zooplankton, weakening its function of phytoplankton consumer, leading to uncontrolled proliferation of microalgae in case of eutrophication. In this study we test the hypothesis that tidal exchanges with the sea can counteract these deleterious effect, by renewing the zooplankton community and by enhancing its top-down control of phytoplankton through selective retention of zooplankton grazers. Our study focused on the southern region of the Gulf of Gabes and the Boughrara lagoon which presents the highest tidal range in the Mediterranean. During two field campaigns (October 2016 and April 2017) we have analyzed zooplankton descriptive (taxonomic composition, abundance; biomass) and functional (ingestion rate, grazing pressure) variables and environmental variables during time series at a fixed station during ebb-flood sequences and at 8 stations along a sea-lagoon transect and during different tidal amplitude periods. Multivariate analyses of both environmental parameters and zooplankton taxa showed the existence of three distinct zones along the sea-lagoon transect, but also the influence of tidal circulation and water mixing on the renewal of the zooplankton community up to the innermost zones of the lagoon. Time series gave clear patterns for the input/output of marine/lagoon species and show a net import for different taxa and for the total zooplankton abundance and biomass (mean flood/ebb ratio $=2.2$ for the total abundance and 2.4 for the biomass), leading to differential retention of zooplankton in the lagoon and to an
\end{abstract}


increase in the potential grazing pressure on phytoplankton (mean flood/ebb ratio $=2.8$ ). We also estimated that the grazing pressure in the lagoon was twice higher during the periods of high tidal amplitudes (at or close to spring tide) compared to periods with low amplitude (neap tides), clearly showing that the retention of zooplankton significantly increases the grazing impact on phytoplankton. These results highlight the importance of the tidal forcing for maintaining the good status of the zooplankton structure and function in strongly anthropized coastal and lagoon ecosystems.

- Keywords: Metazooplankton, lagoon, abundance, biomass, diversity, grazing pressure physical forcing, tidal transport.

\section{Highlights}

Tidal circulation is a major forcing for coastal and lagoon ecosystems.

Tidal forcing maintains zooplankton diversity and community structure.

Tidal exchanges with the sea drive selective retention of zooplankton.

Zooplankton retention increases grazing impact on phytoplankton.

Tidal circulation may limit anthropization effects.

\section{Introduction}

Lagoons and coastal marine zones are both of great importance and high vulnerability at the same time. They are considered as hotspots for biodiversity and are among the most productive ecosystems in the world (Boudouresque, 2004; Basset et al., 2013). They play a key role in the biogeochemical cycles and have a major economic impact through the goods and services they provide (fishing, aquaculture, tourism, etc.). However, their biodiversity and their ecological functioning are threatened by the effects of global change and anthropogenic pressures causing degradation of the biotopes and the biocenosis (Kemp and Boynton 2012). For example, increased anthropogenic activities may accelerate the eutrophication process leading to dystrophic crises and/or irreversible deterioration (Bartoli et al., 2001).

Due to their rapid response to fluctuating physical and chemical conditions, plankton communities are often used as bioindicators for ecological changes in these aquatic systems (Amengual-Morro et al., 2012; Hemraj et al., 2017). In particular, due to its key position in the food webs, zooplankton constitutes a sensitive tool for monitoring environmental changes (Etilé et 
al., 2009; Hussain et al., 2020). Zooplankton comprises larval stages of benthic and pelagic species of high ecological and commercial interest and is particularly abundant in coastal and lagoon systems. As the main consumer of phytoplankton, it constitutes a key factor for controlling proliferation of microalgae and deleterious effects of eutrophication (Rissik et al., 2009). To better analyze the structure and functioning of these ecosystems, to predict, to anticipate and to manage any ecological issues, it is therefore essential to understand the combined effects of natural and anthropogenic forcing and drivers on zooplankton communities.

This was the main issue of the COZOMED-MERMEX project (2014-2018) that was designed to understand whether local physical forcing (including the tide and associated currents) can mitigate the impacts of human disturbance on the structure and functioning of planktonic coastal ecosystems. In particular, we have tested the hypothesis that tidal circulation helps to control the eutrophication through (i) the dilution of the nutritional inputs (bottom-up control) and (ii) retention/accumulation of zooplankton enhancing the grazing pressure on phytoplankton (top-down control). We hypothesize that in high tidal amplitude regions, responses of zooplankton to tidal effects should be considered as a major resilience factor of coastal and lagoon ecosystems against the negative effects of pollution and eutrophication together with the strictly physical effect of tides (dilution linked to increased water turnover rate; Chevalier et al., 2017). According to this hypothesis, the areas under strong tidal influence would be less vulnerable to eutrophication than others.

Retention of zooplankton in such coastal zones is linked to their behavioral responses to tidal currents such as swimming against the flow, downward migration to the low current region and/or active substrate attachment (Alldredge and Hamner, 1980; Genin et al., 2005; Leichter et al., 2013). Tidal currents may also have a positive impact on the import-export dynamics of zooplankton and thus on the renewal of its communities and the maintaining of its biodiversity. The COZOMED-MERMEX project was focused on a Mediterranean coastal ecosystem (Boughrara lagoon - Gulf of Gabes, Tunisia) which has the highest tidal range in the Mediterranean Sea (maximum $>2 \mathrm{~m}$ ). This emblematic ecosystem provides many eco-systemic services (around $65 \%$ of national fishing activities) despite very strong anthropogenic pressure (urban, industrial and agricultural), demonstrating a high resilience capacity (Bejaoui et al., 2019). Thus we may wonder about the direct (eg. dilution) or indirect (zooplankton retention) roles of 
the tidal hydrodynamics on the high resilience capacity of this ecosystem. Previously published results from the COZOMED-MERMEX project have shown the importance of the hydrodynamics in driving certain important ecological features of the Boughrara lagoon: heterogeneous water renewal between zones (Attoui et al., 2020), control of the salinity level inside the lagoon compensating high evaporation (Ben Ismail et al., 2017), accumulation of organic matter inside the lagoon (Ciglenečki et al., 2020), control of toxic algal blooms through control of the distribution of dinoflagellate cysts (Abdelmouleh et al., 2020).

Only few studies have been conducted on zooplankton patterns of distribution and community structure in this region. The first investigation on Boughrara and the southern Gulf of Gabes zooplankton was carried out by Daly Yahia and Romdhane (1994 and 1996) on the diversity and dynamics of the zooplankton community. Before the renovation of the historic Roman causeway, Daly Yahia and Daly Yahia-Kefi (2003) showed that the Boughrara lagoon displayed very high densities of phyto- and zooplankton linked to high water temperature and salinity (comparable to subtropical values) and high nutrient concentrations, particularly orthophosphates, characteristic of an eutrophic region. More recently, Drira et al. (2010) focused on the driving factors of the copepod community structure in the Gulf of Gabes showing the good adaptation of Oithona nana to high salinity and chlorophyll concentrations. However the effect of the tide on the zooplankton has never been investigated.

In this study, we focus on the spatial and time variability of zooplankton under contrasted tidal conditions. We aim to assess the impact of tidal currents on the distribution patterns and the retention of zooplankton to test the hypothesis that these processes may help in limiting the anthropization effects and the ecosystem resilience through maintaining the zooplankton biodiversity and favouring the control of phytoplankton proliferation. 


\section{Methods}

\subsection{Study site}

The Gulf of Gabès is the marine region which has the highest tidal range in the Mediterranean Sea (maximum $>2 \mathrm{~m}$ ) essentially due to the low slope of the continental shelf and the shallow depth, which maintains its horizontal dimensions close to the resonance condition (Bejaoui et al., 2019). The tidal influence is particularly high in the south of the Gulf and in the Boughrara lagoon (Othmani et al., 2017). The Gulf of Gabes is also highly productive and constitutes a paradox in the Eastern Mediterranean basin, which is known to be oligotrophic (Berman et al., 1984; D'Ortenzio and d'Alcalà, 2009; Ben Brahim et al., 2010; Krom et al., 2010). Based on complementary biogeochemical and plankton criteria synthesized from recent regionalization analyses by Ayata et al. (2018), the Gulf of Gabès was recently identified as one of the eleven consensus ecoregions of the Mediterranean and classified as a shallow and phytoplankton bloom region. Linked to this planktonic richness, this area is an important nursery for several fish species (Koched et al., 2015; Enajjar et al., 2015) and contributes approximately 40\% of the national fish production in Tunisia (DGPA, 2015). However, this singular and economically important region was recently identified as a 'hotspot' of anthropogenic pressures (Reygondeau et al., 2017), strongly threatened by industrialization, particularly discharges from large-scale phosphate production plants, and overfishing, both potentially causing ecosystem disequilibrium and the decline of fish resources (Bejaoui et al., 2019).

The Boughrara lagoon $\left(33.35^{\circ} \mathrm{N}, 10.50^{\circ} \mathrm{E}\right)$ is a large $\left(500 \mathrm{~km}^{2}\right)$ and shallow (average depth 
about $5 \mathrm{~m}$ ) basin located in the southwest part of the Gulf of Gabes (Fig. 1). It receives freshwater inputs from small intermittent rivers (wadis) and communicates with the Gulf of Gabes through the Ajim-Jorf channel and with the open Eastern Mediterranean Sea through a $12 \mathrm{~m}$ pass under a Roman causeway linking Djerba Island to the continent. This pass was created in 2007 to promote water exchanges with the sea and water circulation in the lagoon and to make easier water oxygenation and greater mixing of the environment (Guetat et al., 2012). The tide is semi-diurnal with mean amplitude of $31 \mathrm{~cm}$ at neap tide and $73 \mathrm{~cm}$ at spring tide (Othmani et al., 2017). Due to low freshwater inputs and high evaporation, the salinity of the lagoon is higher than in the surrounding sea, reaching values up to 43.6 in the central part of the lagoon and 50.9 at coastal stations, especially during the summer season (Daly Yahia et al., 1994; Ben Aoun et al., 2007).

\subsection{Sampling strategy}

Sampling was carried out during two campaigns within the frame of the COZOMED project: 4-13 October, 2016 (COZOMED 1); 11-14 April 2017 (COZOMED 2), both periods matching strong tidal conditions due to the proximity to equinox periods.

The tidal situation (water height) corresponding to the different samplings is shown in Fig. 2. Sampling was performed in October 2016 and April 2017 at 8 stations: two stations in the marine coastal zone (st 1,12m depth and st 2,8m depth), one station in the Ajim-Jorf channel (st 3,11m depth), one station in the lagoon close to the entrance of the channel (st4, 10m depth), three stations in the central part of the lagoon (st 5 and st 6,14m depth, and st 7, $3 \mathrm{~m}$ depth) and one station in the eastern part of the lagoon close to the Roman causeway and the the pass communicating with the open Mediterranean sea (st 8, 2m depth). In October 2016, these stations were sampled three times to assess spatial variations in three contrasted tidal periods: (1) 4-5 October, with high tidal amplitude (mean $=0.58 \mathrm{~m}$ ) immediately following spring tide conditions (period called HA), (2) 8-9 October with low amplitude (0.22 m) during neap tide (LA) and (3) 11-12 October with medium amplitude (0.38 m) after neap tide (MA). Station 8 located in a very shallow area (as low as $1 \mathrm{~m}$ depth in low water period) was sampled only once on October 5, but was abandoned afterwards due to navigation problems linked to the shallowness. In April 2017, stations 1 to 7 were sampled once (11-14 April) in spring tide conditions with high mean amplitude $(0.67 \mathrm{~m})$. 
In addition, three time-series were performed at station 4 for estimation of sea-lagoon exchanges over a tidal cycle and corresponding to different tidal sequences:

The first series (06 Oct 2016; HA) in post-spring tide period (mean amplitude $=0.49 \mathrm{~m}$ ) started at the beginning of the ebb (10:00), slack water occurred at (15:00) and the two last sampling points were done in flood conditions.

The second series (10 Oct 2016; LA) done during neap tide (mean amplitude $=0.14 \mathrm{~m}$ ) started at the beginning of the flood (10:00), slack water occurred at (14:30) and the three last sampling points were done in ebb conditions.

The third series (12 Apr 2017; HA) performed in spring tide conditions (mean amplitude = $0.66 \mathrm{~m})$ started at the beginning of the ebb (10:00), slack water occurred at (13:30) and the three last sampling points were done in flood conditions.

During each time-series, environmental parameters hourly sampling and zooplankton bi-hourly sampling were performed between 10:00 and 17:00. Note that we were not able to sample over a whole cycle (i.e., between two successive identical tidal situations), for safety reasons.

\subsection{Physical and trophic variables}

Sea level values were obtained from the hydrographic and oceanographic office of the French

Navy (SHOM: Service Hydrographique et Oceanographique de la Marine; http://www.shom.fr/). As the available values from the SHOM concerned the Sfax coastal zone, we applied a 3-h time lag to estimate the values at Boughrara according to the numerical model developed by Othmani et al. (2017). Current velocity and direction were recorded at 10 minute intervals with a current-meter Argonaut D-1500 KHz (http://www.sontek.com/) moored on the bottom close to st 4 (see Fig 1) and deployed from October 6, 2016 for 47 days and from April 13 for 35 days (Attoui et al, 2020). Water origin and renewal time were estimated at each station from the hydrodynamic model described in Zayen et al (2020), using the procedures detailed in Chevalier et al. (2017).

Transparency was estimated with a Secchi disk. Salinity and temperature were recorded using a CTD probe (SBE 37 Sea-Bird Scientific) from surface to bottom. Water samples were collected at two depths (sub-surface and near bottom), using a $5 \mathrm{~L}$ Niskin bottle for measurements of suspended solids (SS), particulate organic matter (POM) and Chloropyll $a$. Chlorophyll $a$ 
was measured by optical density using a Jenway-7605 spectrophotometer. For SS and POM, water samples were filtered onto preweighed GF/F filters. After filtration, filters were dried at $60^{\circ} \mathrm{C}$ for $24 \mathrm{~h}$ and reweighed to determine SS. Afterwards, the filters were burnt at $550^{\circ} \mathrm{C}$ for $1.5 \mathrm{~h}$ and reweighed to estimate ash weight, POM and \% of organic matter (\%POM).

\subsection{Zooplankton}

The zooplankton was sampled with a WP2 $200 \mu \mathrm{m}$ mesh net by vertical hauls from the bottom to the surface. The net was provided with a Hydrobios flowmeter to measure the length of the net trajectory and estimate the sample volume. In addition, samples were collected at two vertical levels (sub-surface and near bottom) with a 30 liter Schindler-Patalas plankton trap (Schindler, 1969) equipped with a $64 \mu \mathrm{m}$ mesh filtering sock. The collected samples were immediately fixed with neutralized formaldehyde ( $4 \%$ final concentration) in hermetically sealed PVC flasks. At the laboratory, before treatment, each sample was washed with $20 \mu \mathrm{m}$ filtered seawater, to eliminate the contained formaldehyde. For both counting and identifying zooplankton taxa, we used a Leica M 205C stereo microscope. For the WP2 samples, taxa were enumerated on sub-samples taken by wide bore piston pipettes, whereas for the trap samples, we counted the individuals on the whole sample. Zooplankton taxa were identified to species level when possible, according to Rose (1933), Tregouboff and Rose (1957), Boxshall and Halsey (2004) and Razouls et al. (2005-2020).

To estimate the body size of zooplankton organisms, selected samples of October 2016 (corresponding to Stations 1, 2, 4, 5, 6 and 7) were digitized with the ZooScan digital imaging system (Gorsky et al., 2010). When necessary, the sample was divided in 2 fractions ( $<1000$ and $>1000$ $\mathrm{mm}$ ) for better representation of rare large organisms in the scanned subsample. The resulting samples were poured onto the scanning cell and zooplankton organisms were manually separated with a wooden spike in order to avoid overlapping organisms. After scanning, each image was processed using ZooProcess, which is embedded in the ImageJ image analysis software (Gorsky et al., 2010). Finally, Plankton Identifier (http://www.obs-vlfr.fr/ gaspari/Plankton_Identifier/ index.php) was used for automatic classification of zooplankton into 7 categories: nauplii, copepod, other crustaceans, appendicularians, chaetognaths, other gelatinous organisms, meroplankton. The mean body area of zooplankton organisms category was then computed for each zooplankton category and for each station 


\subsection{Data analysis}

\subsubsection{Zooplankton abundance and diversity}

Two datasets of zooplankton were considered:

- Subsurface and bottom zooplankton density (trap samples) to examine vertical distribution.

- Mean zooplankton density in the water column; we combined the datasets of the two sampling devices by selecting, for each taxon, the higher value between the trap (mean value of bottom and sub-surface) and the net sample.

In the three time-series at st 4 , for better comparison between the three periods, zooplankton abundance was standardized for each period $\left(\mathrm{x} / \mathrm{x}_{\max }\right)$

The species richness $\mathrm{S}$ is represented by the total or average number of counted species per unit of area. The taxonomic diversity was estimated using the Shannon-Wiener Index $\left(\mathrm{H}^{\prime}\right)$ and Pielou Equitability Index (J ') (Harris et al., 2000). The Pielou Equitability index allows measurement of the distribution of the individuals in each species, independently of the species richness. Its value varies from 0 (dominance of one species) to 1 (equal distribution of the individuals of the species). These indexes were calculated for water column values only, using Primer 6 (Plymouth Routines in Multivariate Ecological Research) Software. To better understand the changes in the community structure, the Rank Frequency Diagrams (RFD) were constructed by plotting the logarithms of the ranks of all species on the $\mathrm{x}$-axis (in decreasing order of frequency) against their logarithmic frequency value on the y-axis (Pinca \& Dallot, 1997). The Importance Value Index (IVI) for the different taxa was determined by summing the values of relative frequency, relative abundance and relative dominance (Curtis, 1959).

\subsubsection{Zooplankton biomass and zooplankton grazing pressure}

The mean body weight of each zooplankton category analyzed with the Zooscan (expressed as $\mu \mathrm{g} \mathrm{C}$ ind $^{-1}$ ) was calculated using the area - carbon body weight relationships from Lehette and Hernandez-Leon (2009). These estimates (based on the analysis of selected samples of October 2016) were averaged per zone (Sea, Transition and Lagoon) and applied to the whole data set. The zooplankton biomass $\left(\mathrm{mg} \mathrm{C} \mathrm{m}^{-3}\right)$ was thus computed by summing the products of the mean individual body weight of each zooplankton category by its density in the water column (ind $\left.\mathrm{m}^{-3}\right)$. 
To estimate the grazing pressure of zooplankton on phytoplankton, we computed the carbon demand of zooplankton (ZCD) based on estimates of its biomass and ration:

ZCD $\left(\mathrm{mgC} \mathrm{m}^{-3} \mathrm{~d}^{-1}\right)=$ Ration $x$ Bzoo

where Bzoo is the biomass of zooplankton in $\mathrm{mgC} \mathrm{m}^{-3}$, and Ration is the amount of food consumed per unit of biomass, calculated as:

Ration $\left(\mathrm{d}^{-1}\right)=(\mathrm{gz}+\mathrm{r}) / \mathrm{A}$

where $\mathrm{gz}$ is the growth rate, $\mathrm{r}$ is the weight specific respiration and $\mathrm{A}$ is assimilation efficiency; gz was calculated following Zhou et al.(2010)

$g z\left(w, T, C_{a}\right)=0.033\left(\frac{C_{a}}{C_{a}+205 e^{-0.125 T}}\right) e^{0.09 T} w^{-0.06}$

as a function of sea water temperature $\left(\mathrm{T},{ }^{\circ} \mathrm{C}\right)$, food availability $(\mathrm{Ca}, \mathrm{mgC} \mathrm{m}-3$, estimated from Chl-a), and weight of individuals (w, mgC).

Following Nival et al. (1975) and Alcaraz et al. (2007), we considered constant values of A (0.7 $\left.\mathrm{d}^{-1}\right)$ and $\mathrm{r}\left(0.16 \mathrm{~d}^{-1}\right)$ respectively.

We compared ZCD to the phytoplankton stock, converted to carbon assuming a classical C:Chla ratio of 50:1, to estimate the potential clearance of phytoplankton by zooplankton.

\subsubsection{Statistical and multivariate analyses}

Sampling point-matrix were created for environmental data (tidal amplitude TA, Secchi depth, $\mathrm{SD}$, temperature T, salinity S, NOx, PO4, Chl (a), suspended solids SS and \% particulate organic matter \%POM) and zooplankton taxa abundance (the 85 taxa reported in Table S1). In each matrix, the columns correspond to the environmental or zooplankton data and the lines to the sampling points. Zooplankton and environmental data were transformed $(\ln x+1)$ before analyses, in order to tend towards normal distribution.

Analysis of variance (ANOVA) was performed to compare mean values of zooplankton and environmental variables between depths, zones and periods. Prior analyses, log transformed data were tested for homogeneity; no case of non-homogeneity was detected.

The spatial and temporal variability of selected environmental variables, the most representative to define zooplankton habitats (temperature, salinity, suspended solids and \% of POM), was investigated using principal component analysis (PCA). The spatial and temporal variability of the zooplankton community was measured using Nonmetric Multi-Dimensional Scaling 
(NMDS) on taxon abundances, based on ordination of similarity matrices using the Bray-Curtis Dissimilarity (Harris et al., 2000). A SIMPER (percentage of similarity) analysis was performed to identify the species contributing most to similarity and dissimilarity between stations for the station groups identified by NMDS. Permutational multivariate analysis of variance (PERMANOVA) was used to compare the station groups defined by the PCA and the NMDS, and test the hypothesis of no differences in community structure among these groups. The analyses were performed using Primer 7 (Plymouth Routines In Multivariate Ecological Research) Software.

According to the interpretation we made on the NMDS on zooplankton, we used the scores of the sampling points on the factorial axes as a proxy to define the "lagoon" or the "marine" character of the zooplankton communities. Then we searched for relationships between these proxies and the water origin (estimated from the hydrodynamic model using the procedures detailed in Chevalier et al., 2017).

\section{Results}

\section{Environmental and trophic variables}

For the October 2016 campaign, the PCA on environmental variables explained $34 \%$ and $33 \%$ of the total variance on the first two components, respectively (Fig.3). The plots of the sampling points on the first axis opposed the coastal marine stations (st 1 and 2) to all other stations characterized by higher salinity, lower SS and higher POM for the three considered tidal periods (HA from 4 to 6 October, LA from 8 to 10 October and MA from 11 to 13 October) (Fig 3A). The second axis tends to oppose the typical lagoon stations (st 5,6 and 7) to the transitional water stations (st3 and 4 close to Ajim-Jorf channel) characterized by lower temperature and lower SS. This pattern on the second axis is followed during the three transects except for st 7 during the MA period, due to a decrease in temperature in this period.

For the April 2017 campaign, the PCA explained 67\% and 28\% of the total variance on the first two components, respectively. The plot of the sampling points (only one transect in HA period), as for October 2016, shows an opposition between marine and lagoon stations (Fig. 3B).

For both periods, the PERMANOVA shows significant differences between the three zones (lagoon, transition area and sea): pseudo $\mathrm{F}=6.3$ and $\mathrm{p}=0.001$ for October and pseudo $\mathrm{F}=6.9$ and 
$\mathrm{p}=0.02$ for April. However, in both periods, pairwise tests show that the differences between the sea and the transition zone or between the sea and the lagoon are more pronounced than the differences between the transition zone and the lagoon, $\mathrm{p}<0.01$ and $\mathrm{p}<0.05$ respectively.

The mean value of the environmental parameters for each zone and each parameter are shown in Table 1. Temperature and salinity were significantly higher in October than in April (ANOVA, $\mathrm{p}<0.001$ ), and in both periods the highest mean values were always found in the lagoon and the lowest in the sea. There was a clear horizontal salinity gradient with salinity increasing from sea (st 1-2) to lagoon (st 5, 6 and 7) with values from 40 to 46 in October and from 38.5 to 42.5 in April. In addition, in both periods, the water was slightly stratified in lagoon and sea zones with a significant difference between bottom and surface salinity (ANOVA, $\mathrm{p}<0.01$ ), but the stratification disappeared in the transition zone. Transparency was higher in October than in April in the lagoon and the transition zone, and the difference was particularly high in the transition zone where the highest values were recorded for both seasons (ANOVA, $\mathrm{p}<0.01)$.

Suspended solid and Chlorophyll $a$ showed no clear spatial pattern, with no significant difference between zones or between bathymetric levels (ANOVA, p>0.1), but were significantly higher in October than in April. Conversely, the percentage of POM was 1.2 to 1.7 times lower in October than in April in all zones.

\section{Zooplankton abundance}

The comparison of surface and bottom zooplankton density values obtained in the samples collected with the plankton trap shows that in October 2016 there was a clear vertical gradient of total zooplankton abundance (expressed as the bottom/surface ratio), with higher abundance near the bottom compared to the surface in the coastal marine stations throughout the survey, and in the transition area during HA period (Fig. 4A). Total zooplankton abundance as well as abundance of the most important taxa (Oithona nana and gastropod larvae) were on average higher in bottom samples than in surface samples when considering the stations as a whole (ANOVA, $\mathrm{p}<0.001$ ). However, when considering each zone separately, the bottom - surface difference was significant only in the coastal marine zone (two-way ANOVAs for bottom-surface and station effects within each zone, $\mathrm{p}<0.05)$. Besides, the relative abundance of the main zooplankton groups (calanoids, cyclopoids and harpacticoids copepods, gelatinous organisms, other holoplankton and meroplankton) displayed no significant variation between surface and 
bottom samples either globally or when considering each zone separately. In April 2016, the bottom - surface ratio varied between 0.5 and 4 according to stations (Fig. 4B), but neither depth nor zone effects were significant for zooplankton abundance or for the percentage abundance of main zooplankton groups (ANOVA, $\mathrm{p}>0.1$ ).

Mean integrated water column values of total zooplankton abundance varied between 3600 and $50000 \mathrm{ind} / \mathrm{m}^{3}$ in October 2016, with high variation according to stations and tidal periods (Fig. 4C). If we except a very low value recorded at station 8 , close to the pass under the Roman causeway, sampled only once on October $5^{\text {th }}$, overall the zooplankton abundance tended to increase from marine stations (st 1 and 2) to lagoon stations (station 5, 6 and 7) in HA and MA periods, whereas no clear spatial pattern was detected during the LA period. The two-way ANOVA (zone and tidal period effects, Table 3) showed that the total zooplankton abundance as well as the abundance of the two most important taxa (Oithona nana and gastropod larvae) were significantly more abundant in the lagoon than in the coastal zone. The percentage of gelatinous organisms significantly increased in the lagoon compared to the sea, mainly due to appendicularians (Oikopleura dioica), whereas the percentage of copepods decreased. Among copepods, the relative abundance of the main groups also changed spatially with decreased importance of Calanoida versus Cyclopoida and Hapacticoida in the lagoon compared to the sea. No significant difference in total abundance or in abundance of the main taxa was observed between tidal periods except for Oithona nana which was significantly more abundant during LA than during MA and HA in the marine and transition zones and conversely in the lagoon. In April 2017, mean integrated water column zooplankton abundance varied between 1400 and $11000 \mathrm{ind} / \mathrm{m}^{3}$ with highest values found in the innermost lagoon stations st 6 and st7 (Fig $4 \mathrm{D}$ ), but no significant difference in total abundance or in abundance of the main taxa was observed between zones except for the percentage of non-copepod and non-gelatinous taxa that was significantly higher in the lagoon than in the coastal area (Table 2).

Overall, the zooplankton abundance was significantly lower in April 2017 than in October 2016 both when considering the three zones separately and for the whole data set (ANOVA, $p<0.01$ ) 


\section{Zooplankton community}

We identified 116 taxa including 64 copepods, 13 non-copepod holoplanktonic crustaceans, 14 gelatinous organisms and 25 meroplanktonic larvae (table S1 in annex). Copepods were always dominant (62\% - 92\% of total abundance) but, in both periods, their percentage decreased from marine to lagoon stations except at station 8 sampled only during HA period in October 2016. Meroplankton, strongly represented by gastropod and bivalve larvae, was the second more important group (4\% - 34\%) and its relative abundance increased from marine to lagoon zone. Gelatinous zooplankton, mainly including appendicularians and chaetognaths, represented < 0.1\%-13\% abundance. Their relative abundance increased from sea to lagoon during October 2016, mainly due to appendicularians (Oikopleura dioica), but displayed an inverse pattern during April 2016.

Among copepods, Oithona nana, Acartia latisetosa, Euterpina acutifrons and Paracalanus parvus were overall the most important species in the 3 zones (sea, lagoon and transition) and in the two periods with IVI ranging between 80 and 130, however A. latisetosa was more prominent in April compared to October (Table S1, Fig. 5). Several other copepod species were recorded only in April (eg Acartia clausi and Tortanus sp.), whereas other species were recorded only in October (eg. Oithona helgolandica, Lubbockia sp., Microsetella sp. and Pontella mediterranea). Most copepod species were recorded in the three zones but several species were absent from the lagoon (Ctenocalanus sp., Pontella mediterranea, Farranula sp., Metridia sp., Heterorhabdus sp.) whereas some others were never recorded in the coastal marine zone (Platycopia pygmea, Oithona simplex, Microsetella sp.).

Among non-copepod taxa, meroplanktonic larvae (namely gastropods, bivalves, polychaetes and cirripedes) as well as the appendicularian Oikopleura dioica were the most strongly represented, with IVI ranging from 60 to 160. Cladocerans, mostly represented by Podon and Evadne genera, were more represented in the lagoon (IVI between 60 and 120) than in the coastal zone (IVI between 0 and 67).

The species richness (S) varied between 20 and 51 with the minimum value found at station 8 . It was significantly higher in October 2016 than in April 2017 (ANOVA, p<0.001). In October 2016, S increased from the sea to lagoon, but displayed the reverse pattern during April 2017. However, species richness and diversity indexes ( $\mathrm{J}^{\prime}$ and $\left.\mathrm{H}^{\prime}\right)$ showed no significant difference 
either between zones in both periods or between tidal periods. H' was significantly higher in October than in April, whereas J' showed no significant difference between the two periods.

The Rank Frequency Diagrams (RFD) had similar convex shapes in both periods and zones except for station 8 in October (Fig. 6). In October, the RFD diagrams were very similar in the 3 considered zones, but station 8 was atypical compared to the other zones, with clear drops after the $1^{\text {st }}$ and the $3^{\text {rd }}$ ranks showing low diversity and evenness compared to the other zones. In April, the RFD of sea and lagoon zones were very similar up to rank 20 but they differed afterwards with spectacular decrease in frequency for the lagoon zone. We can note that in both periods, the RFD observed in the transition zone differed from those of the marine and lagoon zone with slight a drop-off from the $4^{\text {th }}$ (October) or the $6^{\text {th }}$ (April) rank.

In October 2016, Oithona nana was the rank1 species in the three considered zones but differences were observed from rank2, with Phaenna spinifera in the sea zone, Oikopleura dioica in the lagoon and Gastropod larvae in the transition zone (Table 4). Station 8 was dominated by Acartia latisetosa and harpacticoid copepods. In April 2017 the community was dominated by Oithona nana in the marine zone and by gastropod larvae in the transition zone and the lagoon. The NDMS on the relative abundance of the zooplankton taxa clearly discriminated between the two periods sampled (October 2016 and April 2017) as well as between the three identified zones (Fig 7A). In addition, station 8 was clearly distinguished from all other stations. In both periods, the PERMANOVA shows significant differences between the three zones (lagoon, transition area and sea) but with a better discrimination in October (pseudo $F=5.7$ and $\mathrm{p}=0.001$ ) than in April $(\mathrm{F}=2.7$ and $\mathrm{p}=0.017)$. In both periods, pairwise tests show that the differences between the sea and the transition zone or between the sea and the lagoon are more pronounced than the differences between the transition zone and the lagoon $\mathrm{p}<0.01$ and $\mathrm{p}<0.05$ respectively.

In October 2016, to better assess the influence of tidal periods on the lagoon zooplankton community, we performed a NDMS analysis on the relative abundance of zooplankton taxa for the lagoon zone stations (St 5,6 and 7) during the three tidal periods (Fig. 6B). The plot of the sampling points shows a clear separation between the low tidal amplitude period (LA) and periods with higher amplitude (MA and $\mathrm{HA}$ ). In the latter case, the lagoon stations tend to be 
grouped and correlated with the most abundant species (Oithona nana), whereas during the LA period, the sampling points are more scattered.

\section{Zooplankton biomass and zooplankton grazing impact on phytoplankton}

The total zooplankton biomass followed the same spatial and temporal patterns as the zooplankton abundance. The mean biomass values ranged from 5.8 to $36.7 \mathrm{mg} \mathrm{C} \mathrm{m-3}$ with highest values recorded in the lagoon and the transitional zones and the lowest in the coastal marine zone and much higher values in October 2016 than in April 2017 (Table 5). The mean ratio between phyto- and zooplankton biomasses ranges between 8 and $27 \%$. The mean daily grazing pressure represented 4.3 to $15.3 \%$ of the phytoplankton stock, with higher values in October 2016 than in April 2017.

The comparison between tidal periods in October 2016 shows that zooplankton biomass and the zooplankton grazing pressure (ZCD) in the lagoon was on average twice higher during the periods of tidal amplitudes (MA and HA) compared to period with low amplitude (LA), whereas no clear variation was observed between tidal periods in the coastal sea and transitional zones.

\section{Tidal variability at the fixed station}

The total zooplankton abundance increased overall during the ebb period and reached the maximum at low water and until mid-flood, when current velocity was at a maximum and oriented inwards into the lagoon, and tended to decrease afterwards during the end of the flood (Fig. 8A). The percentage of zooplankton present at the surface was highly variable but tended to decrease during the ebb, reaching minimum values from beginning to mid-flood (Fig 8B).

The comparison of the mean values between ebb and flood periods (Fig 9, Table 5) allows assessment of the net tidal exchange of particulate matter and zooplankton between the sea and the lagoon. There was no significant difference between ebb and flood for Chl $a$, SS and $\mathrm{P}$ concentrations (Table 5). In each of the three time-series, the water column integrated total zooplankton abundance and biomass were significantly higher during the flood than during the ebb (Fig. 9). Significant differences between ebb and flood were also found for the water column abundances of copepods (either as total or by larval phases or families), and of the most important copepod species $O$. nana and E. acutifrons, with flood/ebb ratio ranging from 2 to 6 (Table 5). The same patterns were noted for the same zooplankton taxa and additionally for 
total meroplankton and $O$. dioica in bottom strata, but no significant ebb-flood differences were detected in surface water, except for E. acutifrons during the first time-series (October 2016). The water column zooplankton abundance was on average 2.2 higher during the flood than during the ebb, and this increase was even more important for the zooplankton biomass (x 2.4) and for the zooplankton grazing pressure on phytoplankton (x 2.8).

The NMDS performed on the relative abundance of the zooplankton taxa during the two timeseries of October 2016 shows a clear separation between HA and LA periods and between ebb and flood within each period (Fig.10). The first axis clearly shows an opposition between lagoon influence (on the right), through correlation with meroplankton larvae (gastropods, bivalves, polychaetes, fishes, etc) and copepods such as $O$. nana and E. acutifrons, and marine influence (on the left), characterized by more typical marine taxa such as Chaetognaths, Lucifer sp., and copepods such as Metridia sp. LA period was characterized by higher lagoon influence and MA by higher marine influence. Each tidal cycle starts with a relatively marine zooplankton assemblage at high water which then evolves towards a more lagoon assemblage during ebb with a return towards the marine assemblage at the end of the next flood. It can be noted that the return to the marine assemblage is slower than the passage to the lagoon assemblage, particularly during the LA period. Besides, as previously noted spatially in the NMDS for the lagoon stations (see Fig 9), a higher variability was observed in LA conditions compared to HA conditions.

\section{Discussion}

Main characteristics of the Boughrara lagoon zooplankton: do they reflect a disequilibrium? As in many other Mediterranean coastal or lagoon ecosystems (see Table 7), the zooplankton of the Boughrara lagoon is characterized by a community strongly dominated by copepods (62\% - 92\% of total abundance), but also with high relative abundance of meroplanktonic larvae 
(4\% - 34\%; mostly gastropod larvae). Several differences were observed between the two studied periods, with lower abundance and diversity in April 2017 than in October 2016, perhaps reflecting a post spring-bloom situation in April with quick development of some suspensionfeeders (namely, gastropod larvae, and small copepods, see Table 4). This is in agreement with the seasonal variability described by Daly Yahia and Ben Romdhane (1994) for the Boughrara lagoon both in terms of zooplankton abundance and community structure, and similar to the seasonal pattern observed in another Tunisian lagoon: Ghar el Melh (Ziadi et al., 2015). As in most examples given in Table 7, Oithona nana, Acartia latisetosa, Euterpina acutifrons and Paracalanus parvus were overall the most dominant copepod species in the study area in both periods. The high frequency of $O$. nana in the Boughrara lagoon and in its riverine coastal area, both highly anthropized, is not surprising, since this species was already reported at very high and unusual abundance in highly polluted urban bays such as the bay of Toulon in the NW Mediterranean (Richard and Jamet, 2001) or in the bay of Tunis (Daly Yahia et al., 2004). Moreover, the Oithonidae seems to be a family having high affinity for anthropized marine systems, and as such were shown to be a potentially good indicator of anthropization (Serranito et al., 2016) having high dominance in lagoon ecosystems (Williams and Muxagata, 2006). In their pioneering study carried out in 1992-93, Daly Yahia and Ben Romdhane (1994) reported zooplankton abundance in the Boughrara lagoon 2-4 times higher than that recorded in our study in the same seasonal periods, but more than two decades earlier. Furthermore, Centropages kroyeri, which represented 6-10\% of the Boughrara copepod abundance in 1992-93, was almost totally absent in our 2016-2017 samples and was replaced by C. ponticus (2-13\% copepod abundance in the lagoon), recognized as a dominant copepod species throughout the Tunisian lagoons (Neffati et al., 2013). Perhaps this decrease in zooplankton abundance and the replacement of $C$. kroyeri by $C$. ponticus, more adapted to eutrophic conditions, constitute the signs of disturbance of the lagoon plankton ecosystem, in relation to increased anthropization over the last decades, mostly due to chemical pollution which has led to the degradation of the water quality and the erosion of benthic communities (Ben Aoun et al., 2007). Despite these signs of disturbance, the zooplankton community in our study was characterized by a high diversity and evenness and rank frequency diagrams having a convex shape reflecting a relatively mature and equilibrated zooplankton community (sensu Frontier 1976) in the three investigated zones, with the exception of station 8 in October 2016, more characteristic of a young zooplankton community at the beginning of an ecological succession. Conversely other coastal 
Mediterranean ecosystems, strongly anthropized but not under tidal influence, display very low zooplankton diversity, e.g. the small bay of Toulon, where the community is strongly dominated by only one species, Oithona nana reprensenting 60-90\% of the zooplankton abundance) (Jamet and Corbel, 1996).

Another important characteristic of the zooplankton of the Boughrara lagoon is its high abundance, much higher than in the open Mediterranean sea (up to $50000 \mathrm{ind} / \mathrm{m}^{3}$, in our study vs $<10000 \mathrm{ind} / \mathrm{m}^{3}$ in most open Mediterranean regions (Siokou Frangou et al., 2010). In comparison with other lagoons, the zooplankton abundance in the Boughrara lagoon is slightly higher than in the northern Tunisian coastal lagoons, such as Bizerte lagoon (Gueroun et al., 2020) and Tunis lagoon (Annebi Trabelsi et al., 2005), but lower than in the shallow Ghar El Melh lagoon (Ziadi et al., 2015), and within the same range of values as those reported for north-western Mediterranean lagoons such as Thau and Bages-Sigean (Marques et.al., 2015), whereas much higher values are recorded either in highly anthropized sites such as Berre lagoon (Delpy et al., 2012) or in lagoons under low Human pressure (protected areas) such as Sacco del Canarin, (Po Delta, Italy) (Ferrari et al., 1985) and Bardawil (Egypt) (Mageed, 2006). It is interesting to note that the zooplankton abundance and species composition (notably dominance of $O$. nana) in Boughrara are very similar to those recorded in another highly anthropized and mesotidal Mediterranean lagoon, Venice lagoon (Italy) (Riccardi, 2010).

With regard to the Gulf of Gabès, the zooplankton abundance recorded in the southern coastal zone is within the range of that recorded by Drira et al. (2017) in the northern coastal zone close to Sfax and by Drira et al., (2010) in the neritic area (<50m depth), Daly Yahia et al. (2004) found similar zooplankton abundance values in the Bay of Tunis. However, much lower values were recorded in the oceanic areas (>50m depth) of the gulfs of Gabès (Drira et al., 2010) and Tunis (Ben Lamine et al., 2015). 
In summary, despite several signs of disturbance lightened (? alleviated) by the taxonomic composition and presumably linked to the anthropization, the zooplankton community of the Boughrara lagoon is still characterized by high abundance and high diversity reflecting a rather good health status. The rather high biomass ratio between zooplankton and phytoplankton (7$28 \%$, comparable to values reported for coastal marine zones 12-23\%, Gasol et al., 1997), as well as the high zooplankton grazing rate (representing 4.3 to $15.3 \%$ of the phytoplankton stock per day comparable to the values recorded in the open Mediterranean Sea: 9.5 to $19.3 \% \mathrm{~d}^{-1}$; Feliu et al., 2020), are also good signs reflecting an efficient transfer between the first levels of the pelagic food chain. In comparison, other highly anthropized lagoon ecosytems present abnormally low zoplankton/phytoplankton biomass ratio (e.g. $2 \%$ in the Ebrié lagoon, Ivory Coast, Pagano and Saint-Jean, 1994; 1\% in Sontecomapan, VeraCruz, Mexico, Benitez-Diaz Miron et al., 2019) or very low zooplankton grazing impact (e.g. $<1.7 \% \mathrm{~d}^{-1}$ in the Berre Lagoon, NW Mediterranean Sea, Gaudy, 1989), leading to phytoplankton accumulation and episodic dystrophic crisis. Finally, the increasing zooplankton abundance in the Boughrara lagoon compared to the coastal marine area and to the open Mediterranean Sea (see above) suggests zooplankton retention in relation with the morphology (low slope), advection process and the tidal influence, as discussed below.

Tidal influence on community structure and retention of zooplankton: do these processes help maintain zooplankton biodiversity and control phytoplankton?

Our study highlights very clear spatial gradients of environmental and trophic variables between the coastal zone of the Gulf of Gabès and the Boughrara lagoon, but do these changing conditions explain the spatial variability of the zooplankton community and the increasing gradient of zooplankton abundance between the sea and the lagoon? As discussed below, our results suggest rather an important contribution of tidal Lagrangian transport and mixing of organisms from different zones in structuring the zooplankton communities and driving the spatial gradient of zooplankton abundance through selective retention of organisms in the lagoon. The impact of tidal circulation on the exchanges of zooplankton between the sea and the lagoon was clearly shown in the 3 time-series observations performed at station 4 in the transition zone. At this station, the zooplankton community has a relatively marine character at high water which then evolves towards a more lagoon character during the ebb, with a return towards marine character at the end of the next flood (see Fig. 10). In addition, the return to the marine 
character is slower than the passage to the lagoon character, suggesting a dynamic lag between the input and the output of zooplankton from the sea to the lagoon, as observed in hysteresis situations. This pattern is observed in LA and HA periods, but LA, compared to HA, is characterized by having a more lagoon character over the whole tidal cycle, a higher variability in community structure between ebb and flood, and longer time lag from lagoon to marine character (see Fig. 10). This pattern and its variation between LA and HA periods can be explained by the relative contribution of marine and lagoon water in the transition area simulated by the hydrodynamic model (Fig 11A). HA conditions are characterized by an important marine water contribution (Concentration Ratio $\geq 60 \%$ ) compared to lagoon water (15-35\%) (Fig.11A). In LA conditions, the mixing of water is more intensive with a contribution of lagoon water (55$70 \%$ ) that is higher than the contribution of marine water (30-50\%). This may explain the higher variability of the zooplankton community over a tidal cycle during LA than during HA in the transition zone. Furthermore, in each situation, the lagoon character of the community (as defined by the scores of the first axis of the NMDS analysis of Fig 10A) increases when the relative contribution of the lagoon water increases in relation with the tidal cycle (Fig 11B). The lag time for the return to a marine community can be explained by the higher distance of st 4 from the marine coastal zone (st 2) than from the typical lagoon zone (st 5). Thus, the timevariability of the zooplankton community in the transition zone results from mixing of zooplankton taxa differentially transported from the coastal marine area of the Gulf of Gabes and from the innermost part of the lagoon. Tidal exchanges with the open Mediterranean Sea through the Roman causeway in the north-eastern part of the lagoon were not directly investigated, but the very different community recorded at Station 8 compared to the other lagoon stations (see Figs 6 and 7), also suggests intense tidal exchanges and mixing between coastal marine and lagoon zooplankton. Estimates of the water origin and renewal time from the hydrodynamic model confirm the high contribution of the external Mediterranean water $(>50 \%)$ and the intense water renewal ( $<10$ days; Atoui et al., 2020) in this zone of the lagoon. This can thus be considered as a transition zone between the sea and the lagoon, similarly to the northwestern zone close to Ajim-Jorf channel (St 3 and St4). 
Spatial gradients of zooplankton community structure were clearly demonstrated in both periods (Fig 7A). These gradients appear to be strongly driven by tidal advection transport, as suggested by the positive relationships between the lagoon character of the community at the different lagoon stations and the relative contribution of the lagoon water at these stations (Fig 11 C). In the lagoon, spatial gradients of the zooplankton community were clearly higher in LA conditions compared to MA and HA conditions when the strong tidal circulation probably generates mixing and homogenization of the zooplankton communities (see Fig. 7B). This suggests that during high tidal amplitude periods, the communities are spatially homogenized even in the innermost part of the lagoon (st 6 and 7), whereas low amplitude periods favour spatial gradients of zooplankton communities. High tidal amplitudes also favour gradients of abundance (see Fig 4C) linked to a retention phenomenon (see below), but with mixing and homogenization of the community composition linked to higher tidal exchanges with the sea. Conversely, low tidal amplitude would attenuate the gradient of abundance (through lower retention), but would favour a spatial gradient of community composition.

The higher zooplankton abundance recorded in the Boughrara lagoon compared to the adjacent coastal zone in the Gulf of Gabès seems to result from a retention phenomenon associated with tidal currents, as shown by the net import balance of zooplankton especially for the most important copepod species $O$. nana and E. acutifrons, during the tidal cycle (see Fig. 9 and Table 5). Rawlinson et al (2005) also advanced a net tidal transport to explain the higher abundance of mesozoplankton species (including Oithona helgolandica) in a semi-enclosed Irish ecosystem compared to the adjacent Atlantic Ocean. Similarly to our observations in the transition area (st 4), Krumme and Liang (2004) observed higher zooplankton abundance during the ebb with highest values occurring at low water in a Brazilian macro-tidal cul-de-sac channel, suggesting zooplankton retention. However, the higher proportion of meroplankton in the Boughrara lagoon compared to the coastal zone could also indicate that higher zooplankton abundance in the lagoon may arise from local production of meroplanktonic larvae by benthic adults in the lagoon, as mentioned by Archambaud et al., (1988) among different hypotheses to explain increased abundance of organisms inside and outside embayments. Nevertheless, rather high mean flood/ebb ratio for meroplankton abundance (1.4 for the water column and 2.3 for bottom water with significant ebb - flood difference) argue more in favor of meroplankton retention in the lagoon rather than local production of adults. Although we have no current data on benthic communities in the study area, we know that the coastal zone of the Gulf of Gabes 
close to Boughrara hosts a macroinvertebrate benthic community very similar to the one in the lagoon (Khedhri et al., 2016). Moreover, the strong variability of the flood/ebb ratio between the different taxa suggests a selective retention of zooplankton in the lagoon, with copepod and particularly harpacticoids (mostly Euterpina acutifrons) and to a lesser extent the cyclopoid Oithona nana being the most retained taxa. Such selective retention could be partly explained by a behavioral tendency of some species to congregate in the depths during ebb tide, as observed for Acartia in Newport Bay, California, by Trinast (1975). Among Oithonidae, Oithona davisae was shown to have the ability of selective retention and an extremely high adaptive plasticity in Black Sea environment (Svetlichny et al., 2016) and O. plumifera increased abundance in shallow nearshore waters off the south coast of South Africa could also be explained by physical aggregation (Porri et al., 2007).

In our study, significant ebb-flood differences were observed for bottom strata but not in surface waters, also suggesting aggregation of zooplankton at depth during ebb tide, limiting their export from the lagoon. Very similar results were recorded in another mesotidal Mediterranean lagoon (Sacca del Canarin, Adriatic Sea) by Ferrari et al. (1985) who observed particularly high abundance of Acartia clausi, Paracalanus parvus, Oithona nana and Euterpina acutifrons at flood tide compared to ebb tides, as well as daily positive input-output balance for calanoids, cyclopids and harpacticoids over a 24-h cycle. In contrast, Brugnano et al. (2010) in a nontidal lentic ecosystem of the southern Adriatic region (lagoon Lesina) observed an increasing abundance trend from the lagoon towards the sea, highlighting the relative confinement of this lagoon. Besides, this lagoon, similarly to other non-tidal lentic Mediterranean lagoons (e.g. Lakes Ganzirri and Faro, Zagami and Guglielmo, 1995), is characterized by rather low (<10000 ind $/ \mathrm{m}^{3}$ ) zooplankton abundances in contrast to other Mediterranean lagoons such as Boughrara, characterized by intense hydrodynamics and water exchanges with the sea.

In this study we observed net import balances of total zooplankton abundance (mean flood/ebb ratio $=2.2$ ) and biomass (mean flood/ebb ratio $=2.4$ ) during the semi-diurnal tidal cycles leading to an increase of the potential grazing pressure on phytoplankton (mean flood/ebb ratio = 2.8). We also estimated that the grazing pressure in the lagoon was twice higher during the periods of high tidal amplitudes (MA and HA) compared to period with low amplitude (LA), 
clearly showing that the retention of zooplankton significantly increases the top-down control of phytoplankton thus help controlling the proliferation of phytoplankton.

In summary the high tidal exchanges (particularly during spring tide periods) favour mixing and homogenization of the community as well as retention and accumulation of zooplankton in the Boughrara lagoon. These processes help maintain the zooplankton biodiversity even in the innermost part of the lagoon. They also lead to an increase in the zooplankton abundance and biomass and its grazing impact on phytoplankton.

\section{Conclusion}

The comparison of our results with previous historical studies highlights several changes in the zooplankton community composition, probably due to the degradation of environmental and trophic conditions linked to increasing anthropisation. However, several results in our study (high diversity, high abundance and biomass, equilibrated biomass ratio between phyto-and zooplankton, high potential grazing impact) reveal a rather good current health status of the planktonic ecosystem in agreement with our hypothesis of a buffer effect of the tidal flow likely to limit the effects of this anthropization, Our study clearly shows the effect of the tidal forcing (i) on the time variability and on the spatial gradients of community structure and abundance between the marine coastal zone and the innermost part of the lagoon, and on (ii) maintaining high abundance, biomass and grazing pressure in the lagoon. These results suggest the importance of the tidal forcing for maintaining the zooplankton diversity and biomass at a good level in a strongly anthropized ecosystem, thus fulfilling (quantitatively and qualitatively) the stock of zooplankton prey available for the upper trophic levels (zooplanktophagous organisms, e.g. small pelagic fishes) and ensuring a good top-down control of phytoplankton. The topdown control on phytoplankton may be also partly exerted by the micro-zooplankton as shown by Sakka Hlaili et al., (2006) for the Bizerte lagoon where a large ciliate community was shown to prey upon upon large diatom cells. Since there is also an important ciliate community in the Boughrara-Gabès system (Rekik et al., 2020), further studies may necessarily extend the investigations to the whole of the zooplankton (including proto- and metazooplankton) in order to better understand how tidal forces can minimize the devastating impact of eutrophication and contamination. 


\section{Acknowledgements}

The research was carried out in the frame of the project COZOMED-MERMEX (Effets of physical forcing on COastal ZOoplankton community structure: study of the unusual case of a MEDiterranean ecosystem under strong tidal influence) co-funded by the French MAEE (ENVI-MED/MISTRALS AP 2014), the National Institute for Marine Science and Technology (INSTM), and the Institut de Recherche pour le Développement (IRD). This work is part of the $\mathrm{PhD}$ thesis by Nouha Makhlouf Belkahia co-funded by the University of Carthage (bourse d'alternance) and the Institut de Recherche pour le Développement (IRD). We are indebted to Michael Paul, a native English speaker, for proofreading the text. We would also like to acknowledge two anonymous reviewers for their constructive comments and suggestions.

\section{References}

Abdmouleh Keskes, F.A., Ayadi, N., Atoui, A., Mahfoudi, M., Abdennadher, M., Walha, L.D., Ismail, S.B., Abdallah, O.B., Khammeri, Y., Pagano, M., 2020. Dinoflagellates encystment with emphasis on blooms in Boughrara Lagoon (South-Western Mediterranean): Combined effects of trace metal concentration and environmental context. Estuarine, Coastal and Shelf Science 237, 106648.

Alcaraz, M., Calbet, A., Estrada, M., Marrasé, C., Saiz, E., \& Trepat, I. (2007). Physical control of zooplankton communities in the Catalan Sea. Progress in Oceanography, 74(2-3), 294312.

Alldredge, A.L., Hamner, W.M., 1980. Recurring aggregation of zooplankton by a tidal current. Estuar Coast Mar Sci 10, 31-37.

Amengual-Morro, C., Niell, G.M., Martínez-Taberner, A., 2012. Phytoplankton as bioindicator for waste stabilization ponds. Journal of Environmental Management 95, S71-S76.

Annabi Trabelsi, N., Daly Yahia, M.N., Romdhane, M.S., Ben Maiz, N., 2005. Seasonal variability of planktonic copepods in Tunis North Lagoon (Tunisia, North Africa). Cahiers De Biologie Marine 46 (4), 325-333. 
Archambault, P., Roff, J.C., Bourget, E., Bang, B., Ingram, G.R., 1998. Nearshore abundance of zooplankton in relation to shoreline configuration and mechanisms involved. Journal of Plankton Research 20, 671-690.

Atoui, A., Smeti, H., Sammari, C., Ismail, S.B., 2020. Water renewal in the Boughrara lagoon (Tunisia, central Mediterranean Sea) under tidal forcing. Estuarine, Coastal and Shelf Science, 106680.

Ayata, S.-D., Irisson, J.-O., Aubert, A., Berline, L., Dutay, J.-C., Mayot, N., Nieblas, A.-E., D'Ortenzio, F., Palmiéri, J., Reygondeau, G., 2017. Regionalisation of the Mediterranean basin, a MERMEX synthesis. Progress in Oceanography.

Bartoli, M., Nizzolo, D., Viaroli, P., Turolla, E., Castaldelli, G., Fano, E.A., Rossi, R., 2001. Impact of Tapes philippiarum farming on nutrient dynamics and benthic respiration in the Cacca di Goro. Hydrobiologia 455, 203-212.

Basset, A., Elliott, M., West, R., Wilson, J., 2013. Estuarine and lagoon biodiversity and their natural goods and services. Elsevier.

Béjaoui, B., Ismail, S.B., Othmani, A., Hamida, O.B.A.-B.H., Chevalier, C., Feki-Sahnoun, W., Harzallah, A., Hamida, N.B.H., Bouaziz, R., Dahech, S., 2019. Synthesis review of the Gulf of Gabes (eastern Mediterranean Sea, Tunisia): Morphological, climatic, physical oceanographic, biogeochemical and fisheries features.

Ben Aoun, Z., Farhat, F., Couba, L., Hadj Ali, M.S., 2007. Investigation on possible chemical pollution of the Boughrara lagoon, south of Tunisia, by chemical wastes. Bull. Inst. Natn. Scien. Tech. Mer de Salammbô 34, 119-128.

Ben Brahim, M., Hamza, A., Hannachi, I., Rebai, A., Jarboui, O., Bouain, A., Aleya, L., 2010. Variability in the structure of epiphytic assemblages of Posidonia oceanica in relation to human interferences in the Gulf of Gabes, Tunisia. Marine Environmental Research 70, 411421.

Ben Ismail, S., Chevalier, C., Atoui, A., Devenon, J.-L., Sammari, C., Pagano, M., 2017. Water Masses Exchanges Within Boughrara Lagoon-Gulf of Gabes System (Southeastern Tunisia), Euro-Mediterranean Conference for Environmental Integration. Springer, pp. 1589-1590.

Ben Lamine, Y., Pringault, O., Aissi, M., Ensibi, C., Mahmoudi, E., Kefi, O.D.Y., Yahia, M.N.D., 2015. Environmental controlling factors of copepod communities in the Gulf of Tunis (south western Mediterranean Sea). Cahiers De Biologie Marine 56, 213-229. 
Benitez-Diaz Miron, M. I., Castellanos-Paez, M. E., Garza-Mourino, G., Ferrara-Guerrero, M. J., \& Pagano, M. (2018). Biomass, size structure and trophic compartments of the metazooplankton in the Sontecomapan lagoon (Veracruz, Mexico).

Berman, T., Townsend, D., Elsayed, S., Trees, C., Azov, Y., 1984. Optical transparency, chlorophyll and primary productivity in the Eastern Mediterranean near the Israeli coast. Oceanologica Acta 7, 367-372.

Boudouresque, C.-F., 2004. Marine biodiversity in the Mediterranean: status of species, populations and communities. Travaux scientifiques du Parc national de Port-Cros 20, 97-146.

Boxshall, G.A., Halsey, S.H., 2004. An introduction to copepod diversity. Ray Society.

Brugnano, C., Bergamasco, A., Granata, A., Guglielmo, L., Zagami, G., 2010. Spatial distribution and community structure of copepods in a central Mediterranean key region (Egadi Islands-Sicily Channel). J. Mar. Syst. 81, 312-322.

Chevalier, C., Devenon, J., Pagano, M., Rougier, G., Blanchot, J., Arfi, R., 2017. The atypical hydrodynamics of the Mayotte Lagoon (Indian Ocean): Effects on water age and potential impact on plankton productivity. Estuarine, Coastal and Shelf Science 196, 182-197.

Ciglenečki, I., Čanković, M., Kuzmić, M., Pagano, M., 2020. Accumulation of organic matter in a mesotidal Mediterranean lagoon (Boughrara, Tunisia). Estuarine, Coastal and Shelf Science, 106780.

Curtis, J.T., 1959. The vegetation of Wisconsin: an ordination of plant communities. University of Wisconsin Pres.

Daly Yahia, M., Romdhane, M., 1994. Dynamique trophique du Zooplancton et relation Phytoplancton-Zooplancton au sein de l'écosystème de la mer de Bou Grara. Bull Inst Natn Scien Tech Mer de Salammbô 21, 47-65.

Daly Yahia, M., Romdhane, M., 1996. Contribution à la connaissance des cycles saisonnières du zooplancton de la mer de Boughrara (Ensemble de la commuté zooplanctonique). Revue de l'INAT 11, 7-27.

Daly Yahia, M.N., Goy, J., Daly Yahia Kefi, O., 2003. Distribution and ecology of Medusae and scyphomedusae (Cnidaria) in Tunis Gulf (SW Mediterranean). Oceanologica Acta 26 (56), 645-655. 
Daly Yahia, M.N., Souissi, S., Daly Yahia Kefi, O., 2004. Spatial and temporal structure of planktonic copepods in the Bay of Tunis (southwestern Mediterranean Sea). Zoological Studies 43 (2), 366-375.

Delpy, F., Pagano, M., Blanchot, J., Carlotti, F., Thibault-Botha, D., 2012. Man-induced hydrological changes, metazooplankton communities and invasive species in the Berre Lagoon (Mediterranean Sea, France). Mar. Pollut. Bull. 64, 1921-1932.

DGPA, 2015. Annuaire des Statistiques des Pêches en Tunisie (Année 2015). Direction Générale de la Pêche et de l'Aquaculture, Tunis.

d'Ortenzio, F., d'Alcalà, M.R., 2009. On the trophic regimes of the Mediterranean Sea: a satellite analysis. Biogeosciences 6.

Drira, Z., Belhassen, M., Ayadi, H., Hamza, A., Zarrad, R., Bouain, A., Aleya, L., 2010. Copepod community structure related to environmental factors from a summer cruise in the Gulf of Gabes (Tunisia, eastern Mediterranean Sea). J. Mar. Biol. Assoc. U.K. 90, 145-157.

Drira, Z., Sahnoun, H., Ayadi, H., 2017. Spatial distribution and source identification of heavy metals in surface waters of three coastal areas of Tunisia. Development 5, 27.

Enajjar, S., Saidi, B., Bradai, M.N., 2015. The Gulf of Gabes (central Mediterranean Sea): A nursery area for sharks and batoids (Chondrichthyes: Elasmobranchii). Cahiers De Biologie Marine 56, 143-150.

Etile, R.N.d., Kouassi, A.M., Aka, M.N.g., Pagano, M., N'Douba, V., Kouassi, N.g.J., 2009. Spatio-temporal variations of the zooplankton abundance and composition in a West African tropical coastal lagoon (Grand-Lahou, CA ' te d'Ivoire). Hydrobiologia 624, 171-189.

Feliú, G., Pagano, M., Hidalgo, P., \& Carlotti, F. (2020). Structure and functioning of epipelagic mesozooplankton and response to dust events during the spring PEACETIME cruisein the Mediterranean Sea. Biogeosciences 17, 5417-5441.

Ferrari, I., Cantarelli, M.T., Mazzocchi, M.G., Tosi, L., 1985. Analysis of a 24-hour cycle of zooplankton sampling in a lagoon of the Po River Delta. Journal of Plankton Research 7 , 849-865.

Frontier, S., 1976. Utilisation des diagrammes rang-fréquence dans l'analyse des écosystèmes. Journal de la Recherche Océanographique 3, 35-48.

Gasol, J. M., Del Giorgio, P. A., \& Duarte, C. M. (1997). Biomass distribution in marine planktonic communities. Limnology and Oceanography, 42(6), 1353-1363. 
Gaudy, R., 1989. The role of zooplankton in the nitrogen cycle of a Mediterranean brackish lagoon. Sci. Mar. 53, 609-616.

Genin, A., Jaffe, J.S., Reef, R., Richter, C., Franks, P.J.S., 2005. Swimming against the flow: A mechanism of zooplankton aggregation. Science 308 (5723), 860-862.

Gorsky, G., Ohman, M. D., Picheral, M., Gasparini, S., Stemmann, L., Romagnan, J. B., ... \& Prejger, F. (2010). Digital zooplankton image analysis using the ZooScan integrated system. Journal of plankton research, 32(3), 285-303.

Gueroun, S.M., Molinero, J.-C., Piraino, S., Daly Yahia, M.N., 2020. Population dynamics and predatory impact of the alien jellyfish Aurelia solida (Cnidaria, Scyphozoa) in the Bizerte Lagoon (southwestern Mediterranean Sea). Mediterranean Marine Science 21, 22-35.

Guetat, F., Sellem, F., Akrout, F., Brahim, M., Atoui, A., Romdhane, M.S., Daly Yahia, M.N., 2012. Etat environnemental de la lagune de Boughrara et ses alentours deux ans apres les travaux d'amenagement et d'elargissement du pont d'El Kantra. Bull. Inst. Natn. Scien. Tech. Mer de Salammbô 39.

Harris, R.P., Wiebe, P., Lenz, J., Skjoldal, H.R., Huntley, M., 2000. Zooplankton Methodology Manual. Academic Press, London.

Hemraj, D.A., Hossain, M.A., Ye, Q.F., Qin, J.G., Leterme, S.C., 2017. Plankton bioindicators of environmental conditions in coastal lagoons. Estuarine Coastal and Shelf Science 184, 102-114.

Hussain, M.B., Laabir, M., Yahia, M.N.D., 2020. A novel index based on planktonic copepod reproductive traits as a tool for marine ecotoxicology studies. Science of the Total Environment, 138621.

Jamet, J. L., and Ferec-Corbel, A. S. (1996). Seasonal variations of the zooplankton community in a littoral marine ecosystem: Toulon Bay (Var, France). Marine Life, 6(1-2), 3-8.

Kemp, W.M., Boynton, W.R., 2012. Synthesis in estuarine and coastal ecological research: what is it, why is it important, and how do we teach it? Estuaries and Coasts 35, 1-22.

Khedhri, I., Atoui, A., Ibrahim, M., Afli, A., Aleya, L., 2016. Assessment of surface sediment dynamics and response of benthic macrofauna assemblages in Boughrara Lagoon (SW Mediterranean Sea). Ecological Indicators 70, 77-88. 
Koched, W., Alemany, F., Ben Ismail, S., Benmessaoud, R., Hattour, A., Garcia, A., 2015. Environmental conditions influencing the larval fish assemblage during summer in the Gulf of Gabes (Tunisia: South central Mediterranean). Mediterranean Marine Science 16, 666681.

Krom, M., Emeis, K., Van Cappellen, P., 2010. Why is the Eastern Mediterranean phosphorus limited? Progress in Oceanography 85, 236-244.

Krumme, U., Liang, T.H., 2004. Tidal-induced changes in a copepod-dominated zooplankton community in a macrotidal mangrove channel in northern Brazil. Zoological Studies 43 (2), 404-414.

Lam Hoai, T., 1985. Evolution saisonnière du zooplancton dans trois sites peu profonds de Thau, une lagune Nord-Méditerranéenne. Hydobiologia 128, 161-174.

Lehette, P., Hernandez-Leon, S., 2009. Zooplankton biomass estimation from digitized images: a comparison between subtropical and Antarctic organisms. Limnology and OceanographyMethods 7, 304-308.

Leichter, J.J., Aldredge, A.L., Bernardi, G., Brooks, A.J., Carlson, C.A., Carpenter, R.C., Edmunds, P.J., Fewings, M.R., Hanson, K.M., Hench, J.L., 2013. Biological and physical interactions on a tropical island coral reef transport and retention processes on Moorea, French Polynesia. Oceanography 26, 53-63.

Mageed, A.A., 2006. Spatio-temporal variations of zooplankton community in the hypersaline lagoon of Bardawil, north Sinai, Egypt. Egyptian journal of aquatic research: 32, 168-183.

Marques, R., Albouy-Boyer, S., Delpy, F., Carre, C., Le Floc'h, E., Roques, C., Molinero, J.C., Bonnet, D., 2015. Pelagic population dynamics of Aurelia sp in French Mediterranean lagoons. Journal of Plankton Research 37, 1019-1035.

Neffati, N., Yahia-Kefi, O.D., Bonnet, D., Carlotti, F., Yahia, M.N.D., 2013. Reproductive traits of two calanoid copepods: Centropages ponticus and Temora stylifera, in autumn in Bizerte Channel. Journal of Plankton Research 35, 80-96.

Nival, P., Nival, S., \& Thiriot, A. (1975). Influence des conditions hivernales sur les productions phyto-et zooplanctoniques en Méditerranée Nord-Occidentale. V. Biomasse et production zooplanctonique — relations phyto-zooplancton. Marine Biology, 31(3), 249-270.

Othmani, A., Béjaoui, B., Chevalier, C., Elhmaidi, D., Devenon, J.-L., Aleya, L., 2017. Highresolution numerical modelling of the barotropic tides in the Gulf of Gabes, eastern Mediterranean Sea (Tunisia). Journal of African Earth Sciences 129, 224-232. 
Pagano, M., Saint-Jean, L., 1994. Le zooplancton, in: Durand, J.R., Dufour, P., Guiral, D., Zabi, G.S. (Eds.), Environnement et ressources aquatiques de Côte d'Ivoire. Edition ORSTOM, pp. 155-188.

Pinca, S., \& Dallot, S. (1997). Zooplankton community structure in the Western Mediterranean sea related to mesoscale hydrodynamics. Hydrobiologia, 356(1-3), 127-142.

Porri, F., McQuaid, C.D., Froneman, W.P., 2007. Spatio-temporal variability of small copepods (especially Oithona plumifera) in shallow nearshore waters off the south coast of South Africa. Estuarine Coastal and Shelf Science 72 (4), 711-720.

Rawlinson, K.A., Davenport, J., Barnes, D.K.A., 2005. Tidal exchange of zooplankton between Lough Hyne and the adjacent coast. Estuarine Coastal and Shelf Science 62 (1-2), 205-215.

Razouls, C., de Bovée, F., Kouwenberg, J., Desreumaux, N., 2005-2020. Diversité et répartition géographique chez les Copépodes planctoniques marins. http://copepodes.obs-banyuls.fr.

Reygondeau, G., Guieu, C., Benedetti, F., Irisson, J. O., Ayata, S. D., Gasparini, S., \& Koubbi, P. (2017). Biogeochemical regions of the Mediterranean Sea: an objective multidimensional and multivariate environmental approach. Progress in oceanography, 151, 138-148.

Riccardi, N. (2010). Selectivity of plankton nets over mesozooplankton taxa: implications for abundance, biomass and diversity estimation. Journal of Limnology, 69(2), 287-296.

Richard, S., Jamet, J.L., 2001. An unusual distribution of Oithona nana Giesbrecht (1892) (Crustacea : Cyclopoida) in a bay: The case of Toulon Bay (France, Mediterranean Sea). Journal of Coastal Research 17, 957-963.

Rissik, D., Shon, E.H., Newell, B., Baird, M.E., Suthers, I.M., 2009. Plankton dynamics due to rainfall, eutrophication, dilution, grazing and assimilation in an urbanized coastal lagoon. Estuarine Coastal and Shelf Science 84, 99-107.

Rose, M., 1933. Faune de France 26. Copépode pélagiques in: faunistique, O.c.d. (Ed.), Paris, p. 372.

Sakka Hlaili, A., Grami, B., Mabrouk, H. H., Gosselin, M., \& Hamel, D. (2007). Phytoplankton growth and microzooplankton grazing rates in a restricted Mediterranean lagoon (Bizerte Lagoon, Tunisia). Marine Biology, 151(2), 767-783.

Schindler, D., 1969. Two useful devices for vertical plankton and water sampling. Journal of the Fisheries Board of Canada 26, 1948-1955. 
Serranito, B., Aubert, A., Stemmann, L., Rossi, N., Jamet, J.-L., 2016. Proposition of indicators of anthropogenic pressure in the Bay of Toulon (Mediterranean Sea) based on zooplankton time-series. Continental Shelf Research 121, 3-12.

Siokou-Frangou, I., Christaki, U., Mazzocchi, M.G., Montresor, M., d'Alcala, M.R., Vaque, D., Zingone, A., 2010. Plankton in the open Mediterranean Sea: a review. Biogeosciences 7, 1543-1586.

Svetlichny, L., Hubareva, E., Khanaychenko, A., Gubanova, A., Altukhov, D., Besiktepe, S., 2016. Adaptive Strategy of Thermophilic Oithona davisae in the Cold Black Sea Environment. Turkish Journal of Fisheries and Aquatic Sciences 16, 77-90.

Tregouboff, G., Rose, M., 1957. Manuel de planctonologie méditerranéenne, in: Scientifique, C.n.d.1.R. (Ed.), Paris, p. 587

Trinast, E.M., 1975. Tidal currents and Acartia distribution in Newport Bay, California. Estuarine and Coastal Marine Science 3, 165-176.

Williams, J.A., Muxagata, E., 2006. The seasonal abundance and production of Oithona nana (Copepoda : Cyclopoida) in Southampton Water. Journal of Plankton Research 28 (11), 1055-1065.

Zagami, G., Guglielmo, L., 1995. Distribuzione e dinamica stagionale dello zooplancton nei laghi di Faro e Ganzirri. Biologia Marina Mediterranea 2, 83-88.

Zayen, A., Sayadi, S., Chevalier, C., Boukthir, M., Ismail, S.B., Tedetti, M., 2020. Microplastics in surface waters of the Gulf of Gabes, southern Mediterranean Sea: Distribution, composition and influence of hydrodynamics. Estuarine, Coastal and Shelf Science, 106832.

Zhou, M., Carlotti, F., \& Zhu, Y. (2010). A size-spectrum zooplankton closure model for ecosystem modelling. Journal of Plankton Research, 32(8), 1147-1165.

Ziadi, B., Dhib, A., Turki, S., Aleya, L., 2015. Factors driving the seasonal distribution of zooplankton in a eutrophicated Mediterranean Lagoon. Mar. Pollut. Bull. 97, 224-233.

\section{Legends of figures}

Fig. 1. Map of the study zone showing the location of the different sampling stations. AJC=Ajim Jorf Channel; RC=Roman causeway. 
Fig. 2. Tidal situation during the different samplings: position of the sampling points in relation with water height in October 2016 (A) and April 2017 (B). HA, LA and MA (with associated horizontal lines) position the periods of high, low and medium tidal amplitude, respectively.

Fig 3. PCA analysis of the mean values of the main environmental variables (salinity, temperature, SS, POM) for the radial stations in October 2016 (A) and April 2017 (B). HA= high amplitude, LA=low amplitude and MA=medium amplitude. Trans = Transition zone, Lag= Lagoon zone).

Fig.4. Bottom/surface ratio of total zooplankton abundance along coastal marine - lagoon water transects in three tidal periods $(\mathrm{HA}=$ high amplitude, $\mathrm{LA}=$ low amplitude and MA=medium amplitude) in October 2016 (A) and under high amplitude conditions in April 2017 (B) and total integrated water column zooplankton abundance in the same situations ( $\mathrm{C}$ and $\mathrm{D}$ respectively).

Fig. 5. Importance Value Index (IVI) for the copepod taxa in the three zones in October 2016 and April 2017.

Fig 6. Mean Rank Frequency Diagrams (RFDs) of zooplankton taxa for the two campaigns October 2016 (A) and April 2017 (B) and for the three zones (plus St 8 in October).

Fig 7. Non-Metric Multidimensional Scaling (NMDS) of the relative abundance of the zooplankton taxa (square root transformed). Ordination of the sampling points and the zooplankton taxa having correlation $>0.7$ for (A) the two campaigns and (B) for the lagoon stations in October in the three tidal periods. The sampling points of October are symbolized as follows: the station number is followed by -LA, -MA or -HA indicating the tidal period.

Fig 8. Time series of zooplankton abundance standardized for each series (x/xmax) (A) and of \% abundance of zooplankton sampled at the surface (surface x $100 /$ bottom + surface) (B) during ebb/flood at station 4 during the three distinct studied periods. The dashed and continuous black lines correspond to the mean standardized values (between the periods) of water height and current velocity, respectively. For better comparison between the three periods, the results are presented on 
a common $\mathrm{x}$ time scale by positioning the sampling points at the elapse time between the sampling time and the preceding high water.

Fig 9. Comparison of the mean values of total zooplankton abundance (top) and of percentage abundance of the zooplankton groups (bottom) between ebb and flood periods during the three timeseries at Station 4.

Fig 10. Non-Metric Multidimensional Scaling (NMDS) of the abundance of the zooplankton taxa (square root transformed) during the two time-series performed at station 4 in October 6 (HA) and 10 (LA) in 2016. Ordination of the sampling points (A), and the zooplankton taxa having correlation $>0.7(B) . H W+$ number means the elapse time between the sampling time and the preceding high water (e.g. HW+5 means 5 hours after the preceding high water).

Fig 11. Time variation of the relative contribution of lagoon and marine water (derived from the hydrodynamic model; see Methods) at station 4 in October (A), and relationships between the percentage of water of lagoon origin and the 'lagoon character' of the zooplankton during the two timeseries at St 4 in October (B) and for the whole set of stations sampled during the two periods (C). The lagoon character of the zooplankton corresponds to the scores of the sampling points of the first axis of the NMDS of Fig 10A for the time-series, and to the scores of the stations on the second axis of the NMDS of Fig 7A for the spatial variations. 


\section{Legends of Tables}

Table 1. Mean values $( \pm$ SD) of environmental variables in the different zones predefined by the PCA analysis.

Table 2. Mean and standard deviation (SD) values for zooplankton variables in the trap samples collected in subsurface (Surf.) and near bottom (Bot.) for the three zones and the two periods (October and April) and two-way ANOVAs (p values) for the differences between zones and depth; none of the interaction between these effects was significant. Degree of freedom (df) of error were 37 and 12 for October and April, respectively. Significant values of $\mathrm{p}$ are in red characters.

Table 3. Mean and standard deviation (SD) values for integrated water column zooplankton variables in the 3 different zones and for st 8, and one-way (April) or two-way (October) ANOVAs ( $\mathrm{p}$ values) to test the differences between the 3 zones and the 3 tidal periods (LA, HA and MA in October only). Significant values of $\mathrm{p}$ are in red characters.

Table 4. Zooplankton taxa having the first 10 ranks in the RFD diagrams shown in Fig.6.

Table 5. Mean and standard deviation (SD) values for integrated water column values of phytoand zooplankton biomasses and for zooplankton grazing pressure in the 3 different zones and the tidal periods. MA+HA are considered together for comparison with LA.

Table 6. Mean ratio between flood and ebb periods for chlorophyll and particulate matter and for the abundances of total zooplankton and of zooplankton groups or taxa calculated for the integrated water column (Col.) and for the surface (Surf.) and bottom (Bot.) strata and for the biomass and grazing pressure of total zooplankton; T-tests between ebb and flood tide means reveal significantly different means with $\mathrm{p}<0.05(*)$. Ratio corresponding to significant ebb-flood differences are in red characters.

Table 7. Comparison of total zooplankton abundance in different lagoon and coastal ecosystems of the Mediterranean Sea. 
Table S1. Importance value indexes (IVI) for the taxa inventoried during the two COZOMED campaigns in October 2016 and April 2017 in the three zones and at station 8. 


\section{Figures}

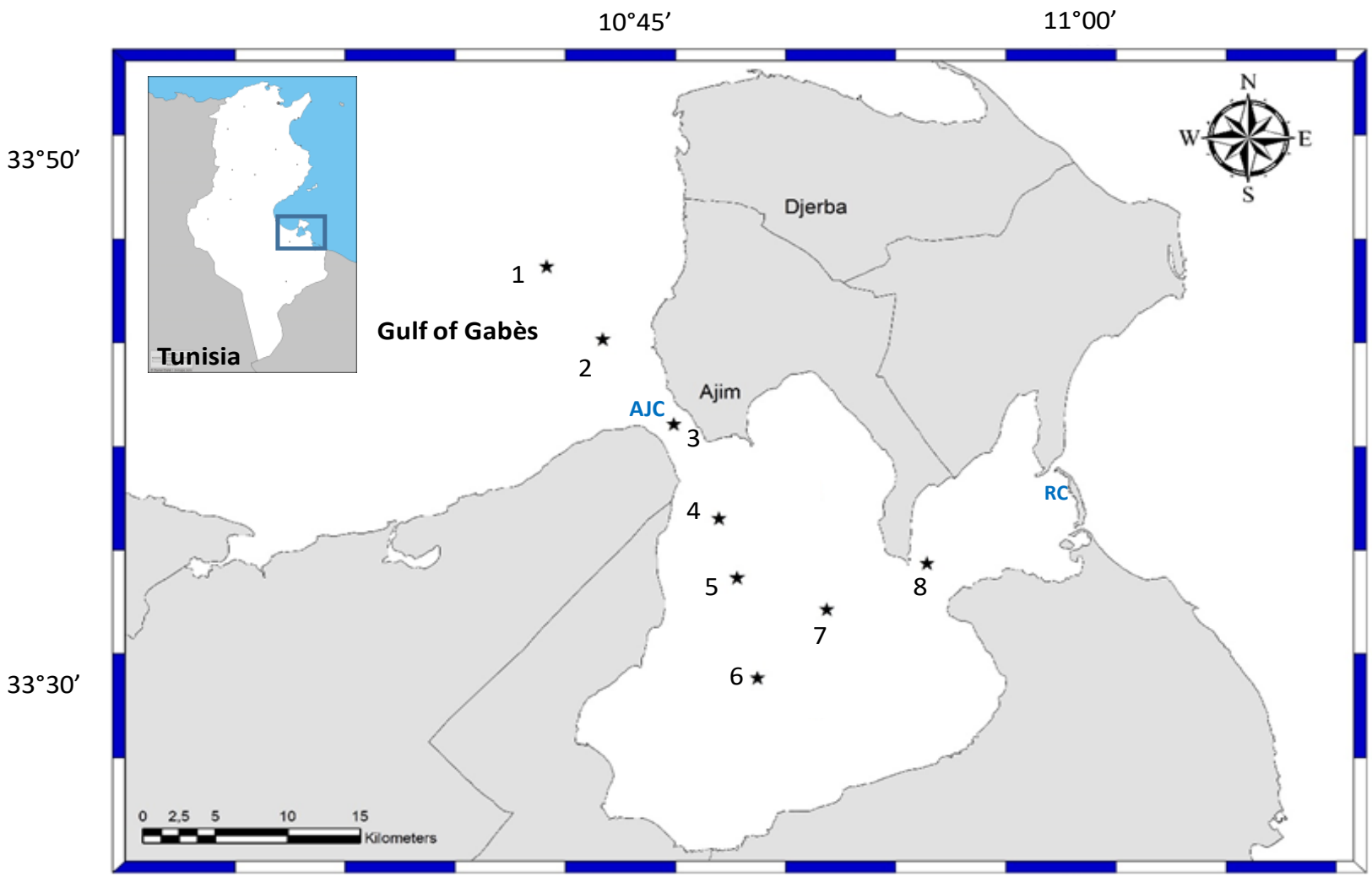

Fig. 1. Map of the study zone showing the location of the different sampling stations. AJC= Ajim Jorf Channel; $\mathrm{RC}=$ Roman causeway.
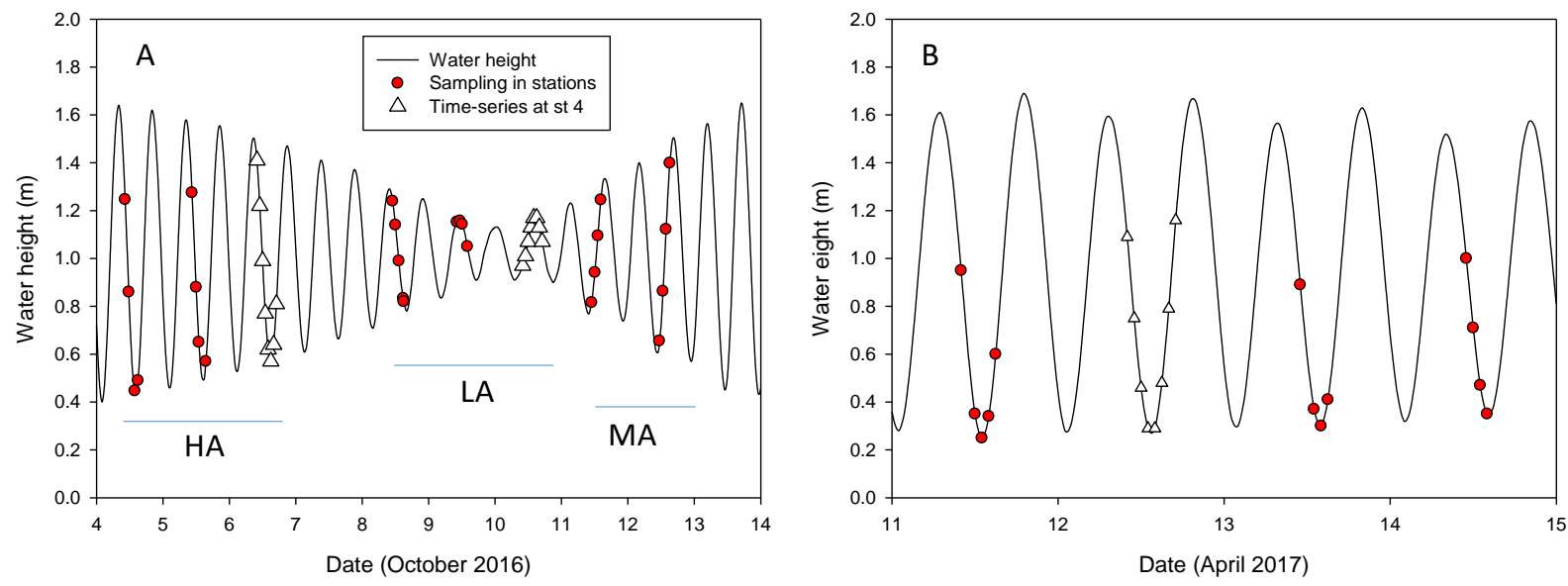

Fig. 2. Tidal situation during the different samplings: position of the sampling points in relation with water height in October 2016 (A) and April 2017 (B). HA, LA and MA (with associated horizontal lines) position the periods of high, low and medium tidal amplitude respectively. 

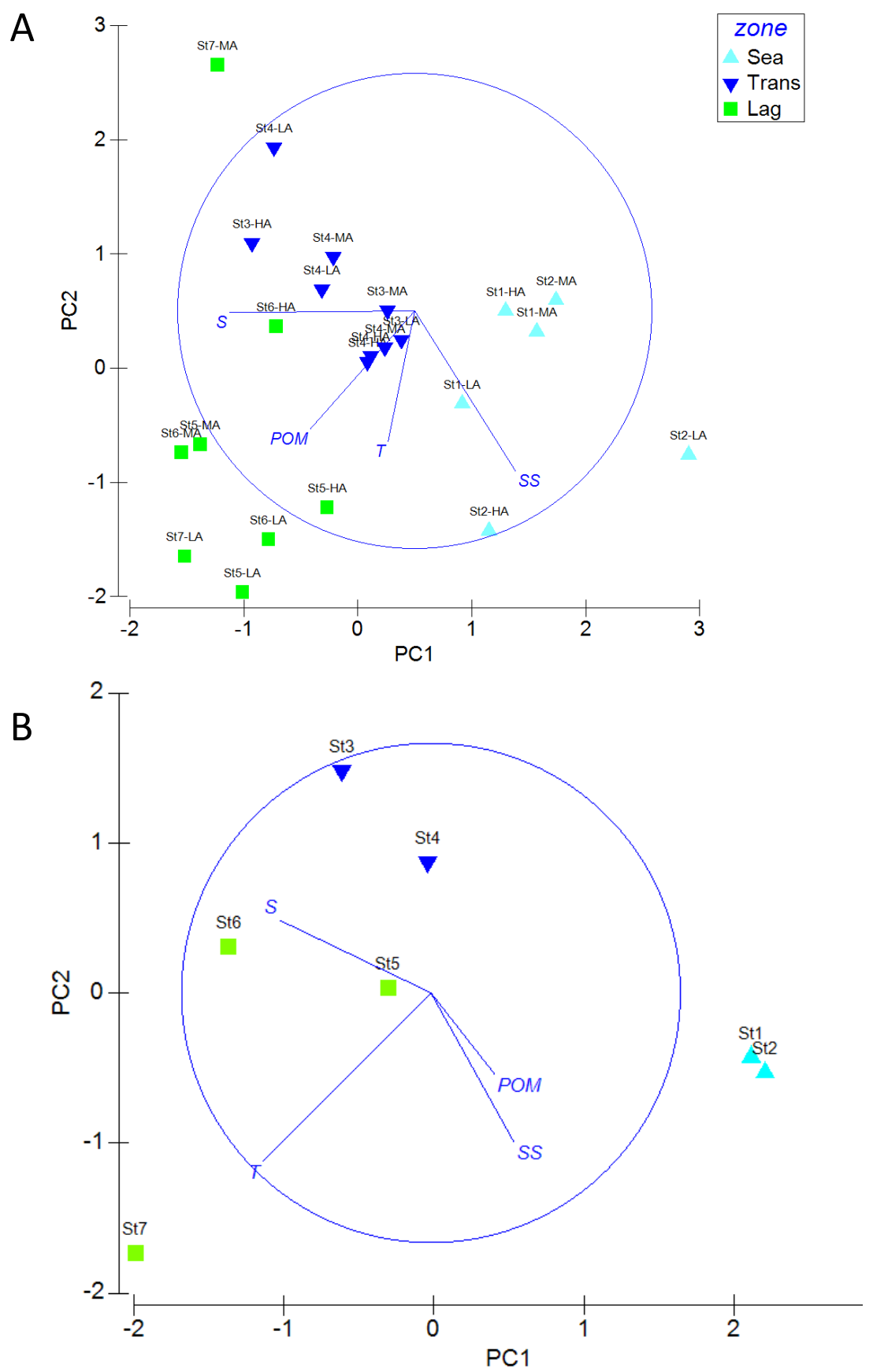

Fig 3. PCA analysis of the mean values of the main environmental variables (salinity, temperature, SS, POM) for the radial stations in October 2016 (A) and April 2017 (B). HA= high amplitude, LA=low amplitude and MA=medium amplitude. Trans $=$ Transition zone, Lag= Lagoon zone). 

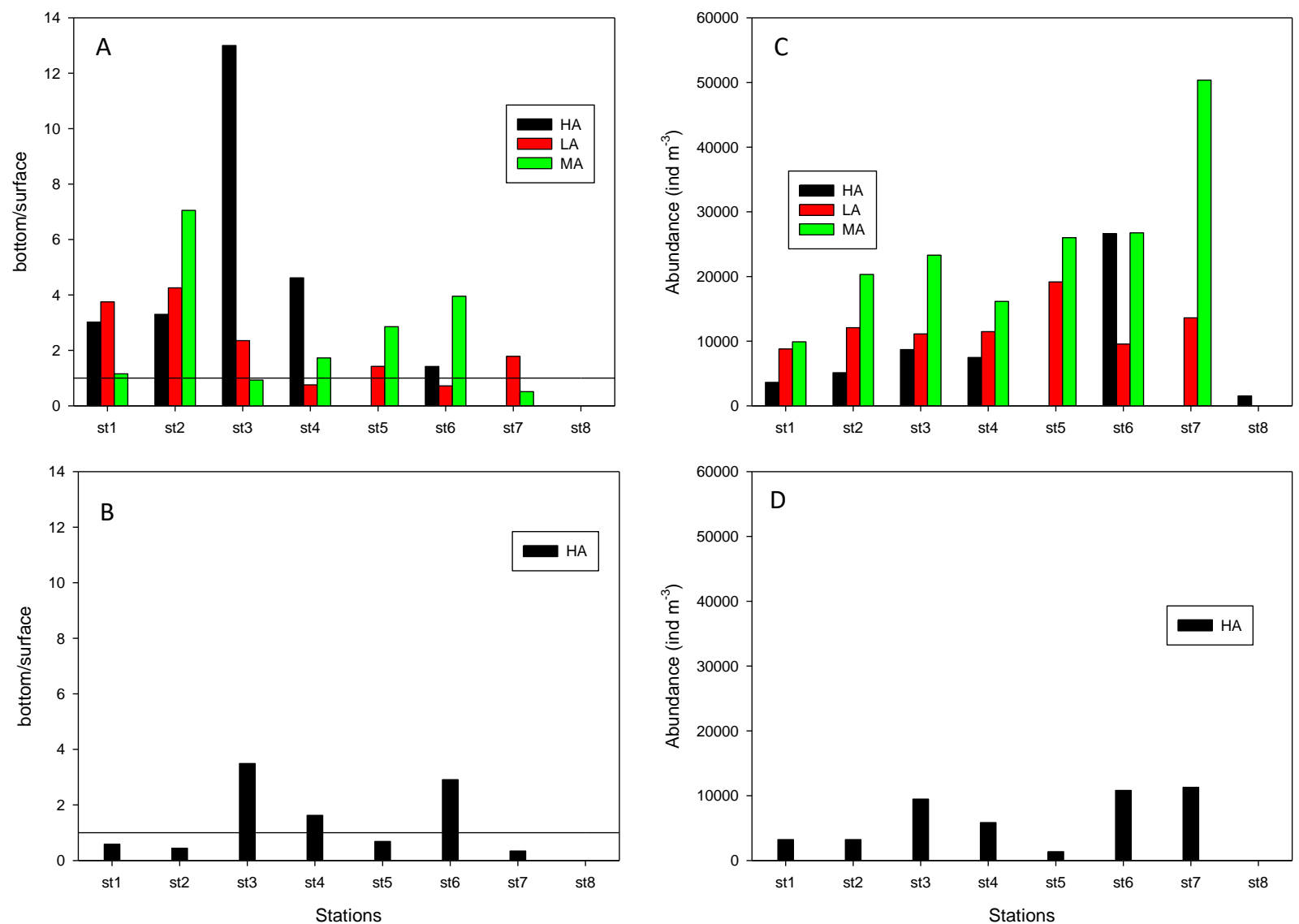

Fig.4. Bottom/surface ratio of total zooplankton abundance along coastal marine-lagoon water transect in three tidal periods $(\mathrm{HA}=$ high amplitude, $\mathrm{LA}=$ low amplitude and $\mathrm{MA}=$ medium amplitude) in October 2016 (A) and under high amplitude conditions in April 2017 (B)and total integrated water column zooplankton abundance in the same situations (C and D respectively). 


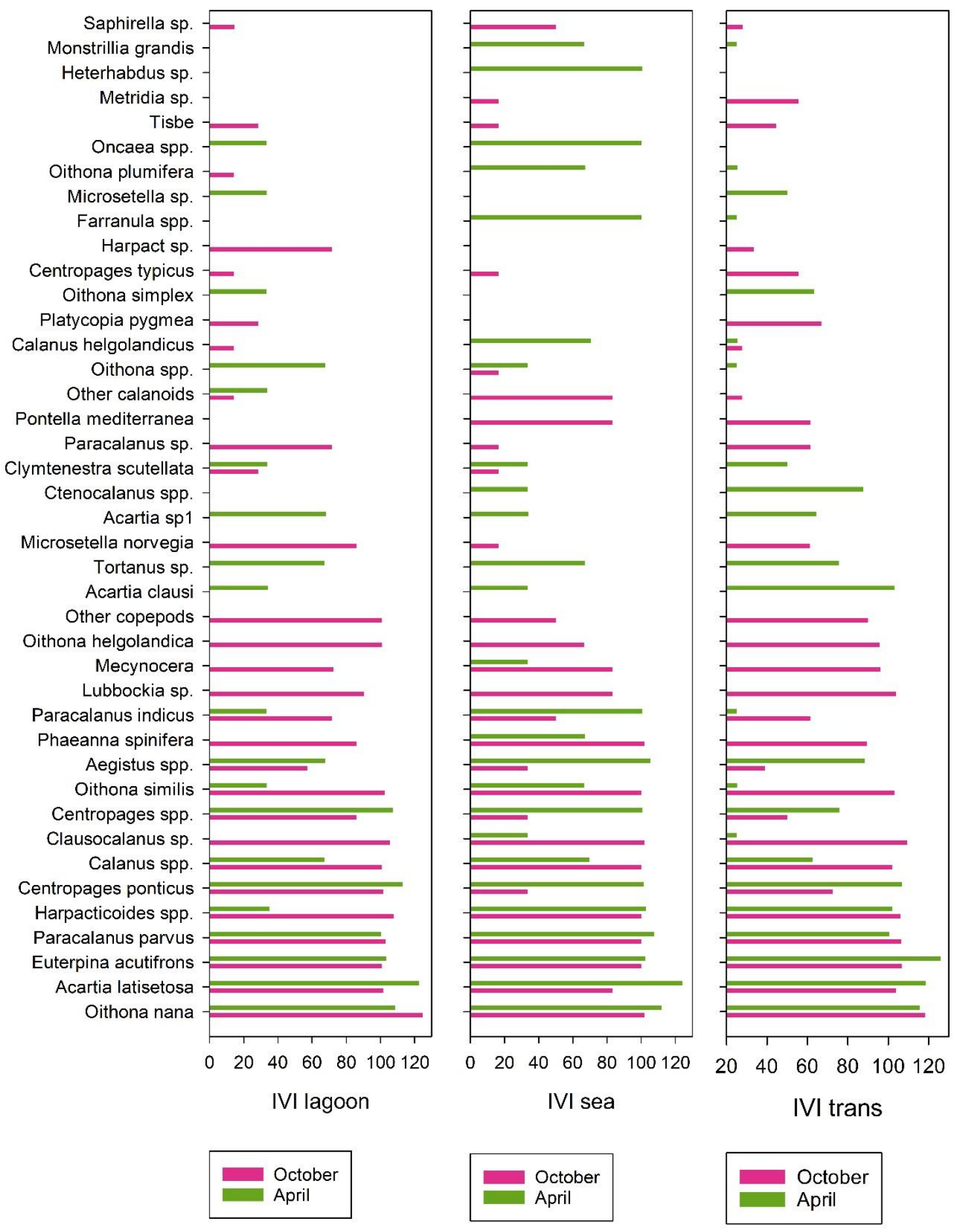

Fig. 5. Importance Value Index (IVI) for the copepod taxa in the three zones in October 2016 and April 2017. 

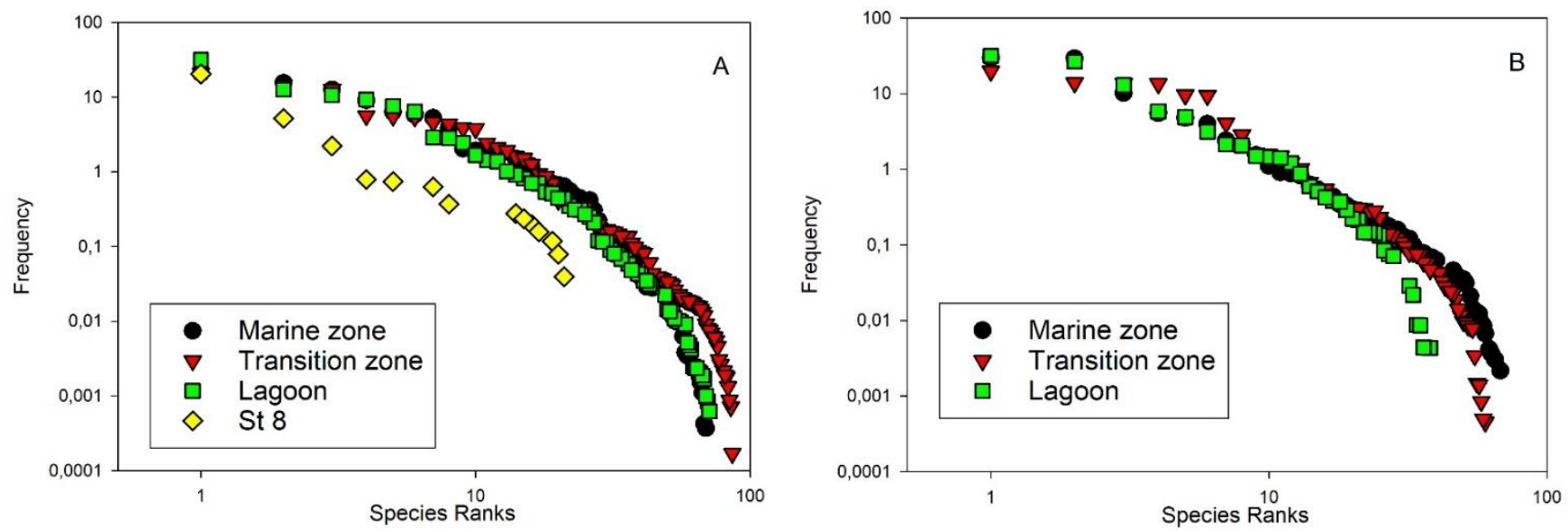

Fig 6. Mean Rank Frequency Diagrams (RFDs) of zooplankton taxa for the two campaigns October 2016 (A) and April 2017 (B) and for the three zones (plus St 8 in October). 


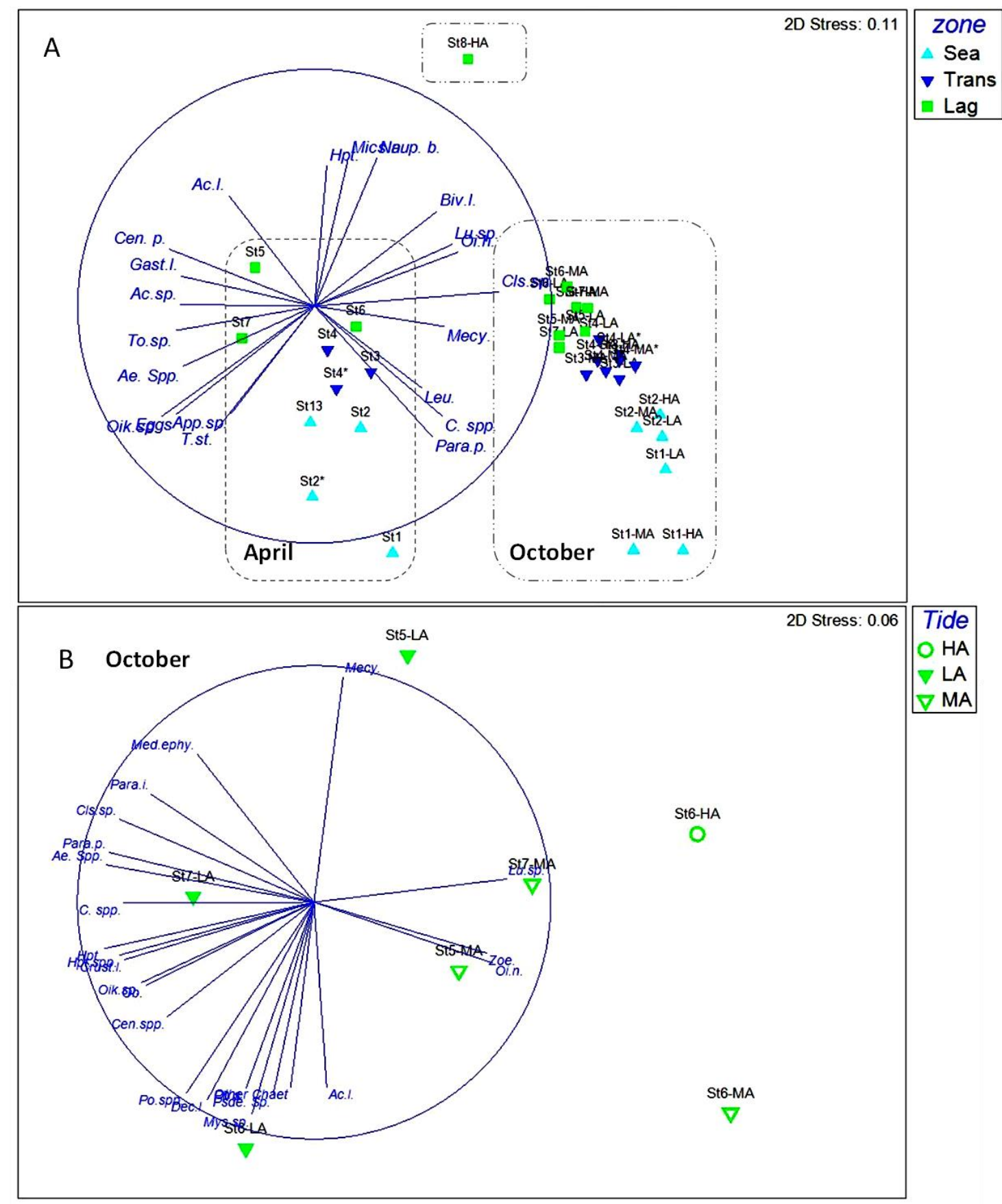

Fig 7. Non-Metric Multidimensional Scaling (NMDS) of the relative abundance of the zooplankton taxa (square root transformed). Ordination of the sampling points and the zooplankton taxa having correlation $>0.7$ for (A) the two campaigns and (B) for the lagoon stations in October at the three tidal periods. The sampling points of October are symbolized as follows: the station number is followed by -LA, -MA or -HA indicating the tidal period. 

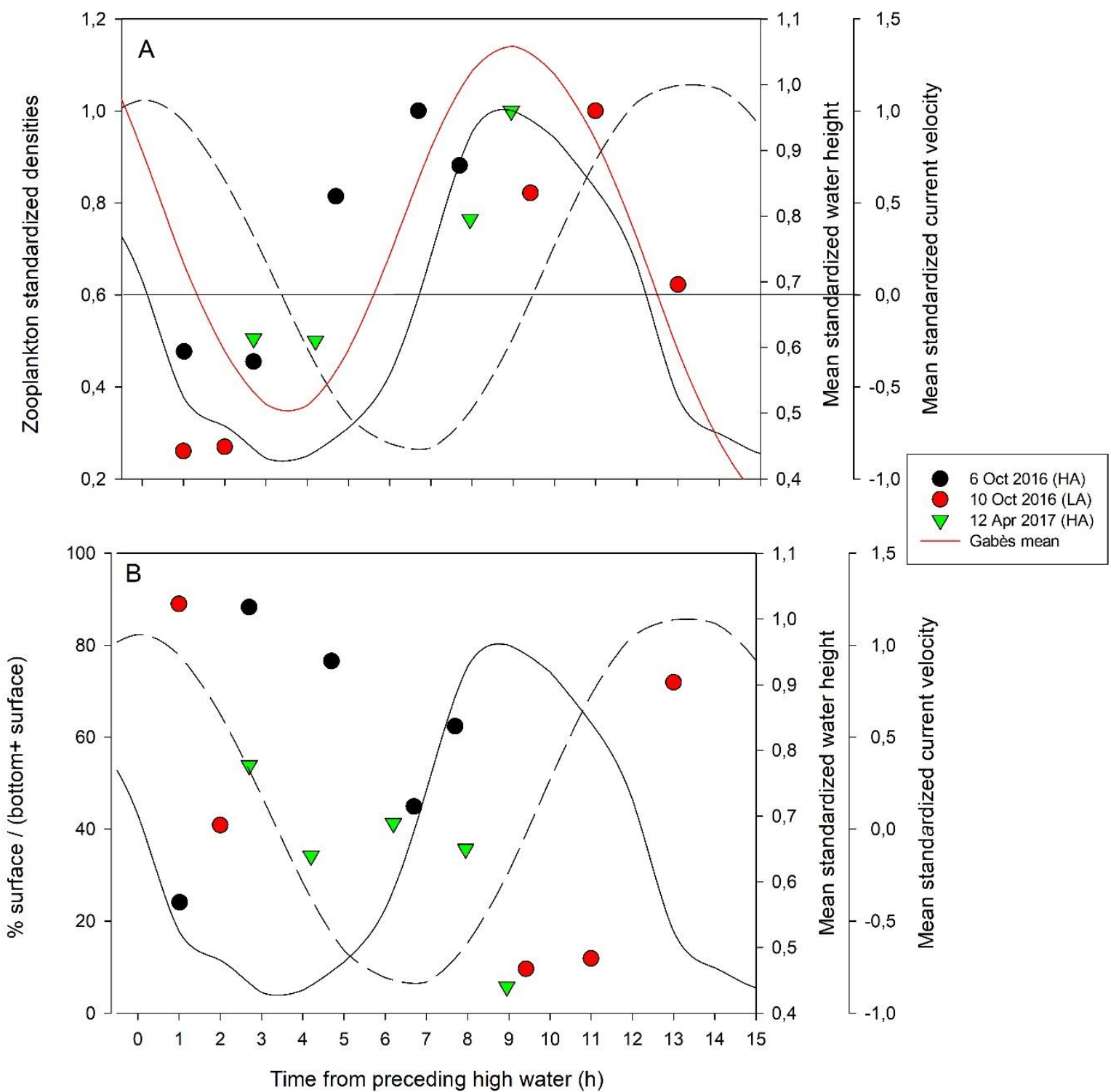

Fig 8. Time series of zooplankton abundance standardized for each series (x/xmax) (A) and of \% abundance of zooplankton sampled at the surface (surface x 100 / bottom + surface) (B) during ebb/flood at station 4 during the three distinct studied periods. The dashed and continuous black lines correspond to the mean standardized values (between the periods) of water height and current velocity, respectively. For better comparison between the three periods, the results are presented on a common $\mathrm{x}$ time scale by positioning the sampling points at the elapse time between the sampling time and the preceding high water" 


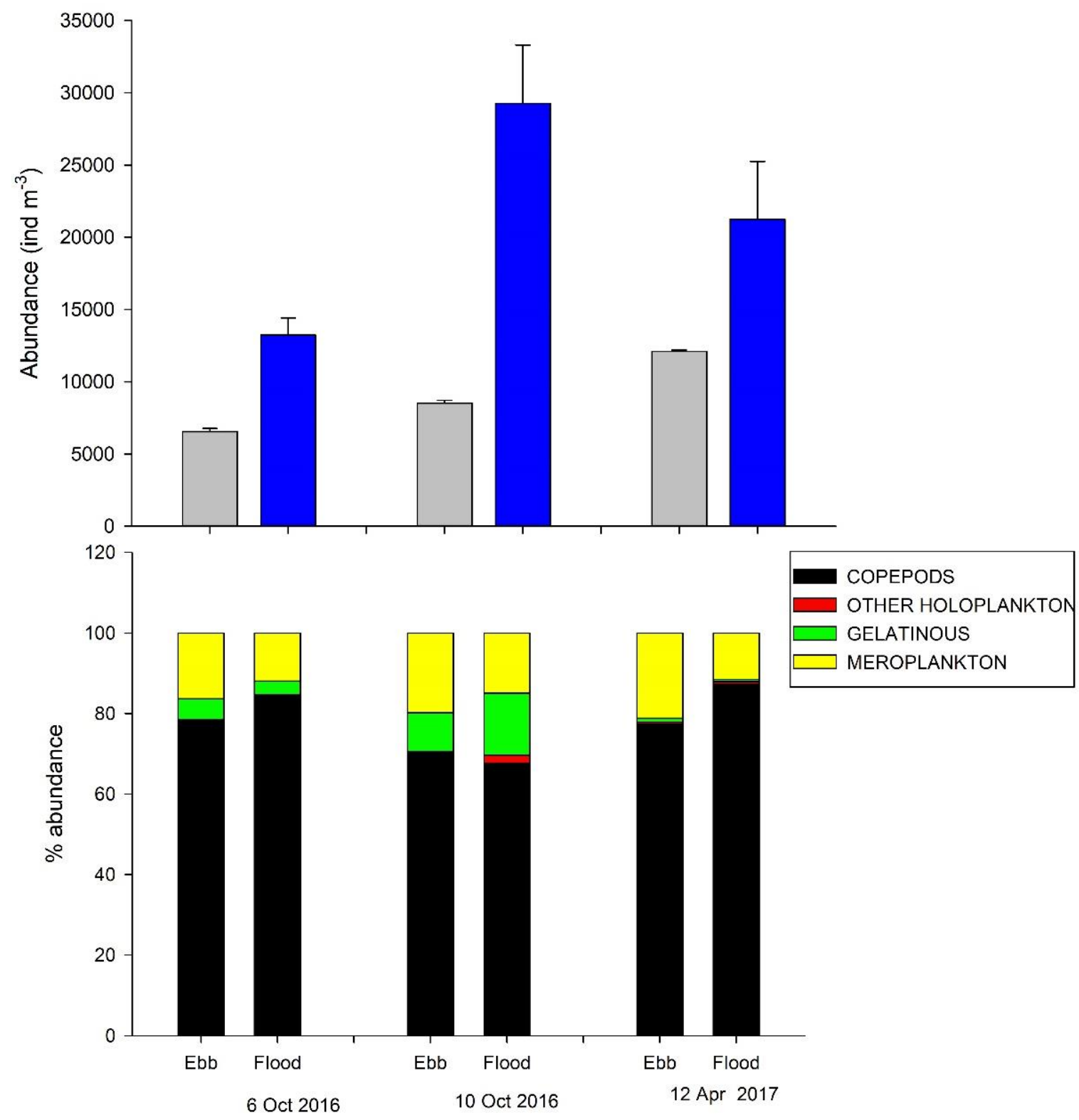

Fig 9. Comparison of the mean values of total zooplankton abundance (top) and of percentage abundance of the zooplankton groups (bottom) between ebb and flood periods during the three time-series at Station 4. 


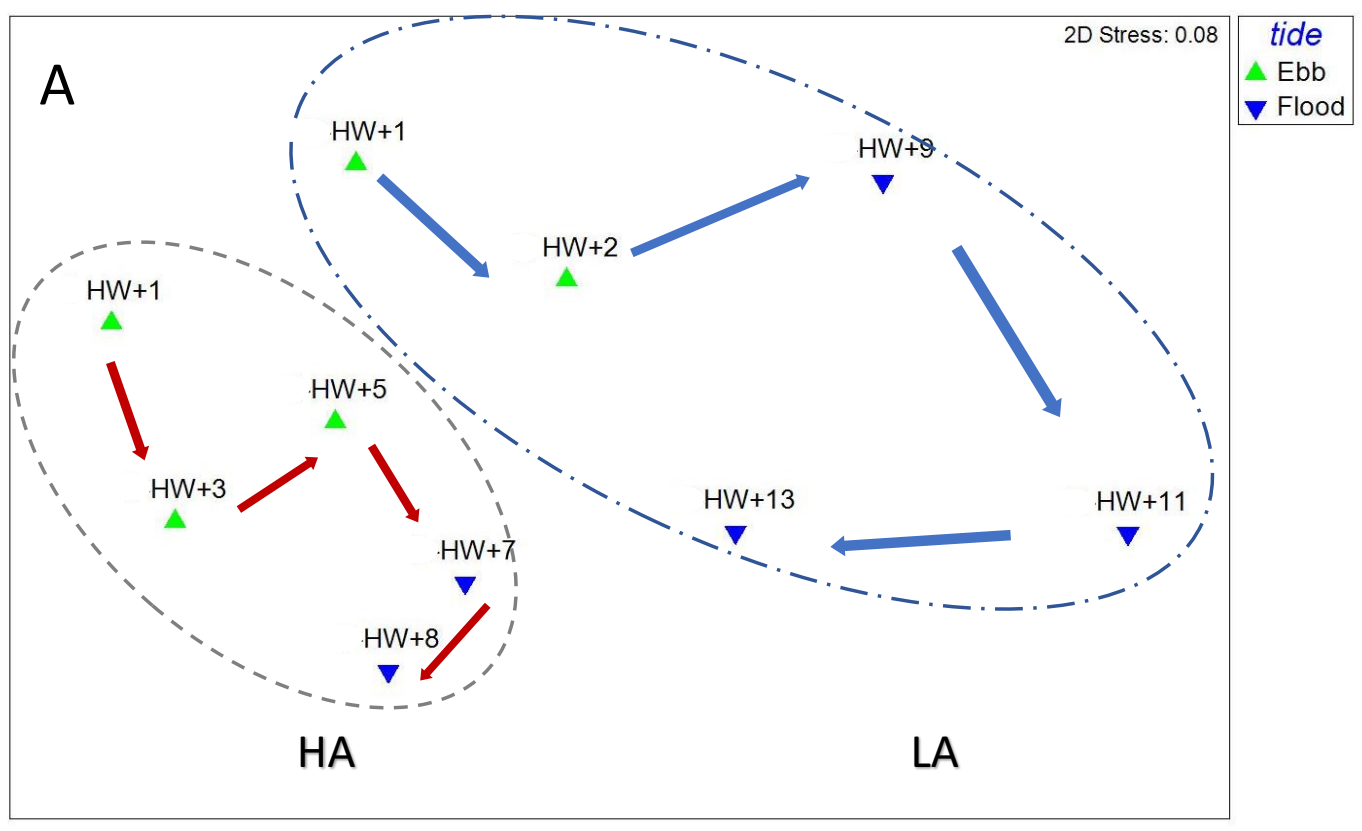

45

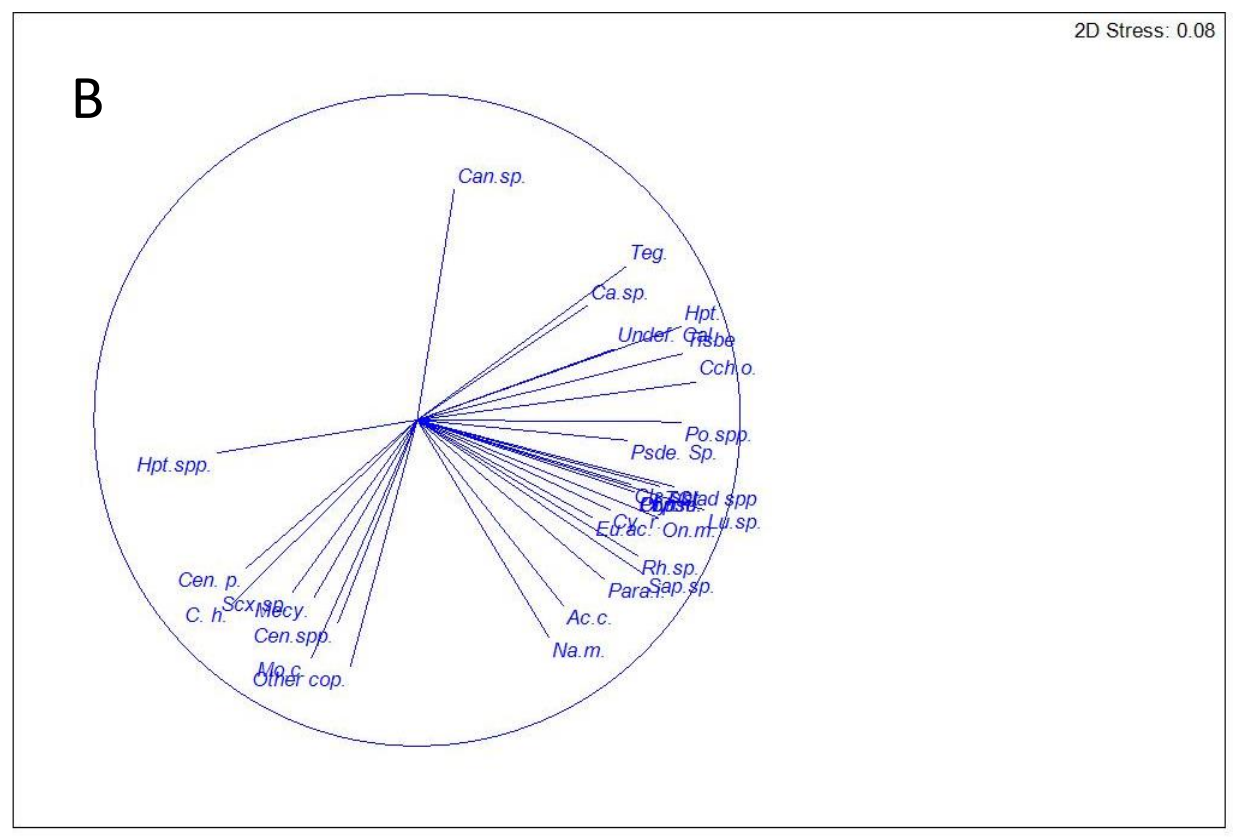

Fig 10. Non-Metric Multidimensional Scaling (NMDS) of the abundance of the zooplankton taxa (square root transformed) during the two time-series performed at station 4 in October 6 (HA) and 10 (LA) in 2016. Ordination of the sampling points (A), and the zooplankton taxa having correlation $>0.7(\mathrm{~B})$. HW+ number means the elapse time between the sampling time and the preceding high water (e.g. HW+5 means 5 hours after the preceding high water). 
A

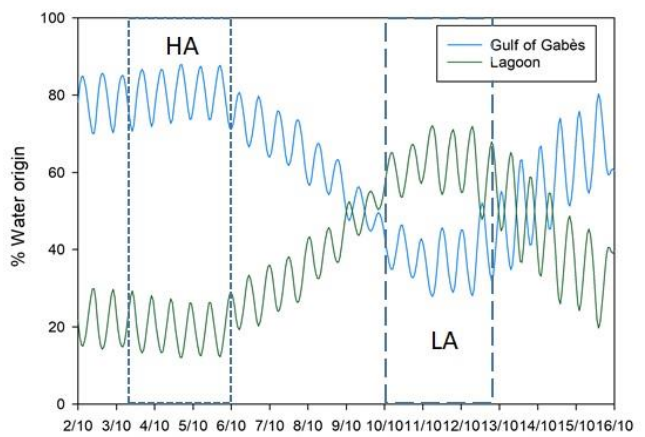

Date

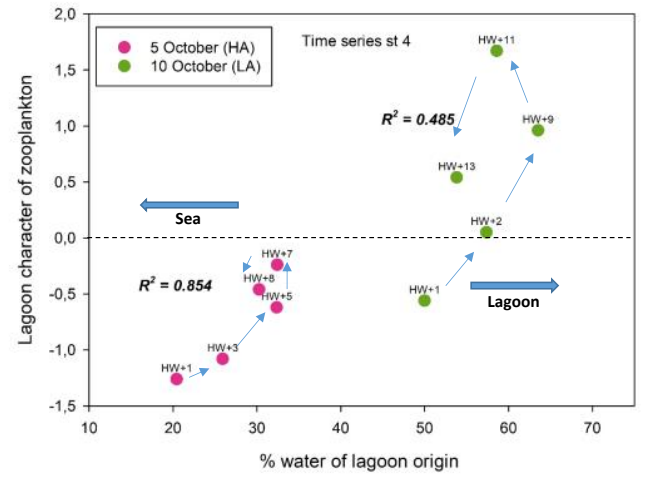

C

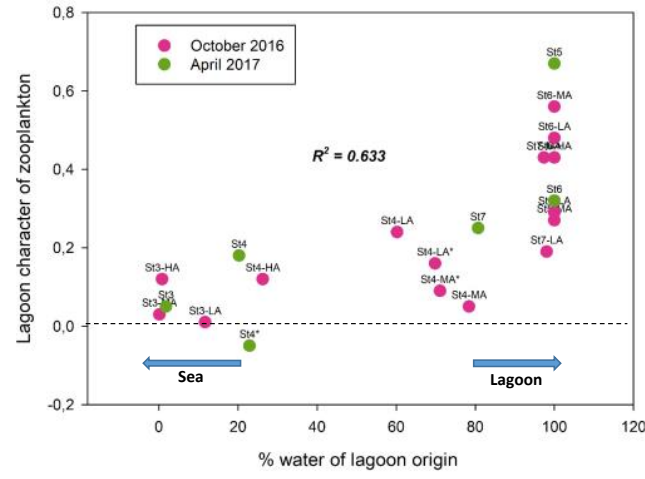

Fig 11. Time variation of the relative contribution of lagoon and marine water (derived from the hydrodynamic model; see methods) at station 4 in October (A), and relationships between the percentage of water of lagoon origin and the 'lagoon character' of the zooplankton during the two time-series at St 4 in October (B) and for the whole set of stations sampled during the two periods (C). The lagoon character of the zooplankton corresponds to the scores of the sampling points of the first axis of the NMDS of Fig 10A for the time-series, and to the scores of the stations on the second axis of the NMDS of Fig 7A for the spatial variations. 


\section{Tables}

Table 1. Mean values $( \pm$ SD) of environmental variables in the different zones predefined by the PCA analysis.

\begin{tabular}{|c|c|c|c|c|c|c|c|c|c|c|c|c|c|c|c|c|c|c|c|}
\hline & \multicolumn{10}{|c|}{ October 2016} & \multicolumn{9}{|c|}{ April 2017} \\
\hline & Sea & & & Trans. & & & Lagoon & & & St8 & Sea & & & Trans. & & & Lagoon & & \\
\hline Salinity & 40.33 & \pm & 0.33 & 43.97 & \pm & 0.67 & 45.48 & \pm & 0.38 & nd & 38.52 & \pm & 0.17 & 42.49 & \pm & 0.01 & 42.58 & \pm & 0.15 \\
\hline Temperature $\left({ }^{\circ} \mathrm{C}\right)$ & 26.66 & \pm & 0.14 & 26.73 & \pm & 0.11 & 26.91 & \pm & 0.22 & nd & 17.65 & \pm & 0.26 & 18.06 & \pm & 0.28 & 19.46 & \pm & 1.24 \\
\hline Transparency $(\mathrm{m})$ & 3.90 & \pm & 0.89 & 7.24 & \pm & 0.14 & 4.80 & \pm & 1.39 & 3.00 & 3.65 & \pm & 0.89 & 4.63 & \pm & 0.18 & 4.30 & \pm & 1.72 \\
\hline Suspended Solids ( $\mu \mathrm{g} / \mathrm{L}$ ) & 24.62 & \pm & 2.32 & 21.39 & \pm & 0.69 & 23.64 & \pm & 1.89 & 28.20 & 11.17 & \pm & 3.31 & 11.16 & \pm & 3.26 & 12.57 & \pm & 2.24 \\
\hline Organic Matter (\%) & 24.54 & \pm & 4.03 & 28.81 & \pm & 1.46 & 28.49 & \pm & 2.64 & 15.60 & 41.84 & \pm & 7.66 & 36.88 & \pm & 0.60 & 33.31 & \pm & 3.34 \\
\hline Total Chl ( $\mu \mathrm{g} / \mathrm{L})$ & 2.98 & \pm & 0.40 & 2.40 & \pm & 1.43 & 5.64 & \pm & 3.09 & 3.19 & 0.78 & \pm & 0.27 & 0.97 & \pm & & 1.50 & \pm & 1.35 \\
\hline
\end{tabular}

Table 2. Mean and standard deviation (SD) values for zooplankton variables in the trap samples collected in subsurface (Surf.) and near bottom (Bot.) for the three zones and the two periods (October and April) and two-way ANOVAs ( $p$ values) for the differences between zones and depth; none of the interaction between these effects was significant. Degree of freedom (df) of error were 37 and 12 for October and April, respectively. Significant values of $p$ are in red characters.

\begin{tabular}{|c|c|c|c|c|c|c|c|c|c|c|c|c|c|c|c|c|c|}
\hline & & \multicolumn{8}{|c|}{ OCTOBER 2016} & \multicolumn{8}{|c|}{ APRIL 2017} \\
\hline & & \multicolumn{6}{|c|}{ Mean values } & \multicolumn{2}{|c|}{ ANOVA ( $p$ values) } & \multicolumn{6}{|c|}{ Mean values } & \multicolumn{2}{|c|}{ ANOVA ( $p$ values) } \\
\hline & & \multicolumn{2}{|l|}{ Sea } & \multicolumn{2}{|l|}{ trans. } & \multicolumn{2}{|l|}{ lagoon } & \multirow{3}{*}{$\begin{array}{l}\text { zone } \\
d f=2\end{array}$} & \multirow{3}{*}{$\begin{array}{l}\text { depth } \\
d f=1\end{array}$} & \multirow{2}{*}{\multicolumn{2}{|c|}{$\begin{array}{l}\text { Sea } \\
n=6\end{array}$}} & \multirow{2}{*}{\multicolumn{2}{|c|}{$\begin{array}{l}\text { trans. } \\
n=3\end{array}$}} & \multirow{2}{*}{\multicolumn{2}{|c|}{$\begin{array}{l}\text { lagoon } \\
n=3\end{array}$}} & \multirow{3}{*}{$\begin{array}{l}\text { zone } \\
d f=2\end{array}$} & \multirow{3}{*}{$\begin{array}{l}\text { depth } \\
d f=1\end{array}$} \\
\hline & & $n=6$ & & $n=8$ & & $n=7$ & & & & & & & & & & & \\
\hline & & Surf. & Bot. & Surf. & Bot. & Surf. & Bot. & & & Surf. & Bot. & Surf. & Bot. & Surf. & Bot. & & \\
\hline \multicolumn{18}{|c|}{ Abundances (ind $/ \mathrm{m}^{3}$ ) } \\
\hline \multirow[t]{2}{*}{ Zooplankton } & mean & 4389 & 15294 & 9867 & 15967 & 20986 & 27210 & 0.008 & 0.033 & 3722 & 1922 & 4189 & 8300 & 7433 & 7144 & 0.277 & 0.770 \\
\hline & $s d$ & 2626 & 11023 & 7015 & 5885 & 20200 & 12082 & & & 880 & 1435 & 1859 & 4100 & 7706 & 7394 & & \\
\hline \multirow[t]{2}{*}{ O. nana } & mean & 411 & 2106 & 1408 & 2738 & 2205 & 3043 & 0.023 & 0.008 & 244 & 122 & 456 & 956 & 400 & 511 & 0.177 & 0.459 \\
\hline & $s d$ & 421 & 2119 & 1145 & 1408 & 1649 & 1897 & & & 192 & 84 & 171 & 738 & 371 & 685 & & \\
\hline \multirow[t]{2}{*}{ L gastero } & mean & 89 & 211 & 779 & 896 & 1238 & 1943 & 0.003 & 0.023 & 489 & 178 & 478 & 1900 & 2156 & 2022 & 0.246 & 0.693 \\
\hline & $s d$ & 72 & 117 & 986 & 833 & 1628 & 1432 & & & 704 & 126 & 184 & 1467 & 2911 & 2528 & & \\
\hline \multicolumn{18}{|c|}{ \% total abundance } \\
\hline \multirow[t]{2}{*}{ Copepods } & mean & 76.6 & 89.5 & 77.4 & 82.2 & 72.6 & 69.0 & 0.013 & 0.217 & 79.0 & 76.1 & 77.0 & 67.7 & 73.5 & 71.2 & 0.730 & 0.443 \\
\hline & $s d$ & 20.2 & 4.3 & 9.8 & 5.2 & 7.3 & 8.1 & & & 17.7 & 17.7 & 8.1 & 5.5 & 15.0 & 8.2 & & \\
\hline \multirow[t]{2}{*}{ Gelatinous } & mean & 0.8 & 0.7 & 2.8 & 3.4 & 8.1 & 11.6 & 0.000 & 0.090 & 2.1 & 3.0 & 1.6 & 4.6 & 2.0 & 0.1 & 0.437 & 0.602 \\
\hline & $s d$ & 0.6 & 1.2 & 1.6 & 2.0 & 4.1 & 3.6 & & & 1.8 & 5.2 & 1.4 & 3.4 & 1.5 & 0.1 & & \\
\hline \multirow[t]{2}{*}{ Other } & mean & 0.7 & 0.1 & 1.0 & 0.1 & 0.9 & 1.2 & 0.728 & 0.419 & 0.0 & 0.3 & 0.2 & 0.0 & 0.1 & 2.3 & 0.126 & 0.104 \\
\hline & $s d$ & 0.7 & 0.2 & 2.9 & 0.2 & 0.9 & 1.7 & & & 0.0 & 0.6 & 0.3 & 0.0 & 0.1 & 2.3 & & \\
\hline \multirow[t]{2}{*}{ Meroplank. } & mean & 21.9 & 9.7 & 18.7 & 14.3 & 18.5 & 18.3 & 0.585 & 0.109 & 18.9 & 20.6 & 21.3 & 27.7 & 24.4 & 26.4 & 0.774 & 0.636 \\
\hline & sd & 20.0 & 3.5 & 9.1 & 3.9 & 9.8 & 6.4 & & & 19.3 & 20.1 & 9.6 & 7.1 & 16.1 & 10.2 & & \\
\hline \multicolumn{18}{|c|}{ \% copepod abundance } \\
\hline Calanoida & $\begin{array}{l}\text { mean } \\
s d\end{array}$ & $\begin{array}{l}72.0 \\
17.6\end{array}$ & $\begin{array}{c}58.8 \\
15.0\end{array}$ & $\begin{array}{l}33.4 \\
6.2\end{array}$ & $\begin{array}{c}33.8 \\
10.4\end{array}$ & $\begin{array}{r}26.1 \\
13.2\end{array}$ & $\begin{array}{l}\mathbf{2 8 . 0} \\
10.3\end{array}$ & 0.000 & 0.368 & $\begin{array}{l}43.1 \\
23.6\end{array}$ & $\begin{array}{l}42.0 \\
12.4\end{array}$ & $\begin{array}{l}\mathbf{2 6 . 4} \\
6.5\end{array}$ & $\begin{array}{l}26.4 \\
9.8\end{array}$ & $\begin{array}{l}63.1 \\
34.2\end{array}$ & $\begin{array}{r}49.8 \\
25.0\end{array}$ & 0.083 & 0.637 \\
\hline Cyclopoida & mean & 15.8 & 27.3 & 37.1 & 41.8 & 49.7 & 46.7 & 0.000 & 0.247 & 38.8 & 37.6 & 40.8 & 41.8 & 26.5 & 31.4 & 0.376 & 0.830 \\
\hline & $s d$ & 11.3 & 13.3 & 8.2 & 14.1 & 18.6 & 12.5 & & & 16.7 & 15.2 & 3.2 & 7.8 & 25.6 & 12.9 & & \\
\hline Harpacticoida & mean & 10.4 & 13.3 & 27.8 & 22.5 & 22.6 & 24.1 & 0.000 & 0.709 & 18.1 & 20.4 & 32.8 & 31.8 & 10.4 & 18.4 & 0.052 & 0.583 \\
\hline & $s d$ & 8.5 & 4.8 & 5.6 & 6.5 & 12.8 & 4.7 & & & 7.1 & 12.2 & 9.6 & 12.6 & 9.1 & 16.6 & & \\
\hline Other copepods & mean & 1.7 & 0.6 & 1.6 & 2.0 & 1.6 & 1.2 & 0.648 & 0.677 & 0.00 & 0.00 & 0.00 & 0.00 & 0.00 & 0.38 & 0.397 & 0.337 \\
\hline & $s d$ & 2.5 & 1.4 & 2.7 & 1.5 & 2.2 & 1.2 & & & 0.00 & 0.00 & 0.00 & 0.00 & 0.00 & 0.66 & & \\
\hline
\end{tabular}


Table 3. Mean and standard deviation (SD) values for integrated water column zooplankton variables in the 3 different zones and for st 8, and one way (April) or two-way (October) ANOVAs ( $p$ values) to test the differences between the 3 zones and the 3 tidal periods (LA, HA and MA in October only). Significant values of p are in red characters.

\begin{tabular}{|c|c|c|c|c|c|c|c|c|}
\hline \multicolumn{6}{|c|}{ OCTOBER 2016} & \multicolumn{3}{|c|}{ APRIL 2017} \\
\hline & \multicolumn{3}{|c|}{ mean values } & \multicolumn{2}{|c|}{ ANOVA ( $p$ values) } & & mean values & \multirow{2}{*}{$\begin{array}{l}\text { ANOVA ( } p \text { values) } \\
\text { zone }\end{array}$} \\
\hline Sea & trans. & lagoon & St. 8 & zone & Tide & Sea & trans. lagoon & \\
\hline$n=6$ & $n=8$ & $n=7$ & $n=1$ & $d f=2$ & $d f=1$ & $n=3$ & $n=3$ & $d f=2$ \\
\hline
\end{tabular}

\begin{tabular}{|c|c|c|c|c|c|c|c|c|c|c|c|}
\hline \multicolumn{12}{|l|}{ Abundances (ind $/ \mathrm{m}^{3}$ ) } \\
\hline \multirow[t]{2}{*}{ Zooplankton } & mean & 9974 & 12143 & 24581 & 1537 & 0.010 & 0.055 & 3223 & 7055 & 7823 & 0.319 \\
\hline & $s d$ & 2425 & 1983 & 5002 & & & & 1110 & 1502 & 3231 & \\
\hline \multirow[t]{2}{*}{ O. nana } & mean & 1258 & 2000 & 2624 & 17 & 0.063 & 0.034 & 183 & 706 & 456 & 0.245 \\
\hline & $s d$ & 449 & 373 & 537 & & & & 109 & 223 & 245 & \\
\hline \multirow[t]{2}{*}{ L gastero } & mean & 150 & 646 & 1590 & 17 & 0.004 & 0.193 & 333 & 1189 & 2090 & 0.259 \\
\hline & $s d$ & 31.3 & 257.1 & 391.0 & & & & 397 & 468 & 1041 & \\
\hline \multicolumn{12}{|l|}{ \% total abundance } \\
\hline \multirow[t]{2}{*}{ Copepods } & mean & 85.2 & 81.8 & 69.8 & 91.1 & 0.001 & 0.204 & 80.7 & 74.3 & 73.1 & 0.612 \\
\hline & sd & 3.0 & 1.6 & 2.4 & & & & 9.8 & 0.8 & 7.8 & \\
\hline \multirow[t]{2}{*}{ Gelatinous } & mean & 0.8 & 3.1 & 9.6 & 1.2 & 0.000 & 0.970 & 3.2 & 3.6 & 1.0 & 0.268 \\
\hline & $s d$ & 0.4 & 0.6 & 0.7 & & & & 1.7 & 1.5 & 0.5 & \\
\hline \multirow[t]{2}{*}{ Other } & mean & 0.6 & 0.7 & 1.2 & 0.3 & 0.542 & 0.929 & 0.2 & 0.2 & 1.1 & 0.013 \\
\hline & $s d$ & 0.3 & 0.3 & 0.4 & & & & 0.3 & 0.2 & 0.1 & \\
\hline \multirow[t]{2}{*}{ Meroplank. } & mean & 13.4 & 14.4 & 19.5 & 7.3 & 0.083 & 0.131 & 15.9 & 21.9 & 24.8 & 0.613 \\
\hline & $s d$ & 2.8 & 1.4 & 2.3 & & & & 11.1 & 2.1 & 8.3 & \\
\hline \multicolumn{12}{|l|}{ \% copepod abundance } \\
\hline \multirow[t]{2}{*}{ Calanoida } & mean & 61 & 34 & 28 & 86 & 0.004 & 0.658 & 65.9 & 43.5 & 64.3 & 0.295 \\
\hline & $s d$ & 6 & 2 & 4 & & & & 15.2 & 8.1 & 13.0 & \\
\hline \multirow[t]{2}{*}{ Cyclopoida } & mean & 25 & 41 & 47 & 1 & 0.016 & 0.191 & 23.7 & 30.6 & 22.4 & 0.580 \\
\hline & $s d$ & 5 & 3 & 5 & & & & 9.6 & 3.4 & 7.4 & \\
\hline \multirow[t]{2}{*}{ Harpacticoida } & mean & 13 & 24 & 23 & 13 & 0.0412 & 0.3845 & 10.3 & 25.9 & 13.1 & 0.125 \\
\hline & $s d$ & 2 & 2 & 3 & & & & 5.9 & 5.3 & 5.4 & \\
\hline \multirow[t]{2}{*}{ Other copepods } & mean & 1 & 1 & 1 & 0 & 0.991 & 0.495 & 0.1 & 0.0 & 0.2 & 0.541 \\
\hline & $s d$ & 1 & 0 & 0 & & & & 0.1 & 0.0 & 0.2 & \\
\hline \multirow[t]{2}{*}{ Specific Richness (S) } & mean & 37.2 & 39.5 & 43.0 & 21.0 & 0.642 & 0.111 & 36.0 & 32.3 & 25.0 & 0.284 \\
\hline & $s d$ & 4.4 & 5.3 & 5.5 & & & & 5.3 & 11.0 & 5.6 & \\
\hline \multirow[t]{2}{*}{ Equitability (J') } & mean & 0.71 & 0.73 & 0.68 & 0.42 & 0.058 & 0.224 & 0.70 & 0.69 & 0.61 & 0.457 \\
\hline & $s d$ & 0.07 & 0.02 & 0.05 & & & & 0.10 & 0.07 & 0.09 & \\
\hline \multirow[t]{2}{*}{ Shannon-Wiener ( $\left.\mathrm{H}^{\prime}\right)$} & mean & 3.70 & 3.85 & 3.69 & 1.85 & 0.078 & 0.156 & 3.59 & 3.39 & 2.84 & 0.112 \\
\hline & $s d$ & 0.43 & 0.09 & 0.24 & & & & 0.34 & 0.22 & 0.50 & \\
\hline
\end{tabular}


Table 4. Zooplankton taxa having the first 10 ranks in the RFD diagrams shown in Fig.6.

\begin{tabular}{|c|c|c|c|c|c|}
\hline & Rank & Sea & Transition & Lagoon & Station 8 \\
\hline \multirow{10}{*}{ October 2016} & 1 & Oithona nana & Oithona nana & Oithona nana & Acartia latisetosa \\
\hline & 2 & Phaeanna spinifera & Gastropods Larvae & Oikeuplora dioica & Harpacticoides spp. \\
\hline & 3 & Paracalanus parvus & Clausocalanus sp. & Bivalve Larvae & Phaeanna spinifera \\
\hline & 4 & Calanus spp. & Euterpina acutifrons & Gastropods Larvae & Bivalve Larvae \\
\hline & 5 & Clausocalanus sp. & Larve bivalve sp1 & Clausocalanus sp. & Nauplii balanus \\
\hline & 6 & Euterpina acutifrons & Oikeuplora dioica & Lubbockia sp. & Oithona nana \\
\hline & 7 & Mecynocera & Paracalanus parvus & Harpacticoides spp. & Euterpina acutifrons \\
\hline & 8 & Decapods larvae & Harpacticoides spp. & Nauplii chthamalus & Microsetella norvegia \\
\hline & 9 & Annelid polychet larvae & Oithona similis & Paracalanus parvus & Oikeuplora dioica \\
\hline & 10 & Bivalve Larvae & Lubbockia sp. & Oithona similis & Nauplii chthamalus \\
\hline & Rank & Sea & Transition & Lagoon & \\
\hline \multirow{10}{*}{ April 2017} & 1 & Oithona nana & Gastropods Larvae & Gastropods Larvae & \\
\hline & 2 & Oikeuplora dioica & Euterpina acutifrons & Oithona nana & \\
\hline & 3 & Gastropods Larvae & Acartia latisetosa & Centropages ponticus & \\
\hline & 4 & Euterpina acutifrons & Oithona nana & Acartia latisetosa & \\
\hline & 5 & Acartia latisetosa & Centropages ponticus & Euterpina acutifrons & \\
\hline & 6 & Paracalanus parvus & Oikeuplora dioica & Annelid polychet larvae & \\
\hline & 7 & Lubbokia acuelata & Harpacticoides spp. & Harpacticoides spp. & \\
\hline & 8 & Aegistus spp. & Annelid polychet larvae & Centropages spp. & \\
\hline & 9 & Harpacticoides spp. & Acartia sp1 & Acartia sp1. & \\
\hline & 10 & Calanus helgolandicus & Acartia clausi & Podon spp. & \\
\hline
\end{tabular}


Table 5. Mean and standard deviation (SD) values for integrated water column values of phyo- and zooplankton biomasses and for zooplankton grazing pressure in the 3 different zones and the tidal periods. MA+HA are considered together for comparison with LA.

\begin{tabular}{|c|c|c|c|c|c|c|c|c|c|c|}
\hline & & \multicolumn{6}{|c|}{ OCTOBER 2016} & \multicolumn{3}{|c|}{ APRIL2017 } \\
\hline & & \multicolumn{2}{|l|}{ Sea } & \multicolumn{2}{|c|}{ transition } & \multicolumn{2}{|l|}{ lagoon } & \multirow{2}{*}{$\begin{array}{l}\text { Sea } \\
\text { HA }\end{array}$} & \multirow{2}{*}{$\begin{array}{l}\text { trans } \\
\mathrm{HA}\end{array}$} & \multirow{2}{*}{$\begin{array}{l}\text { lagoon } \\
\mathrm{HA}\end{array}$} \\
\hline & & LA & $\mathrm{HA}+\mathrm{MA}$ & LA & $\mathrm{HA}+\mathrm{MA}$ & LA & $\mathrm{HA}+\mathrm{MA}$ & & & \\
\hline \multicolumn{11}{|c|}{ Biomasses (mgC m-3) } \\
\hline \multirow[t]{2}{*}{ Phytoplankton } & mean & 169.7 & 138.5 & 128.6 & 137.2 & 219.8 & 196.0 & 51.4 & 48.6 & 74.8 \\
\hline & $s d$ & 4.9 & 15.0 & 54.3 & 72.0 & 68.8 & 64.0 & 25.0 & 25.0 & 67.6 \\
\hline \multirow[t]{3}{*}{ Zooplankton } & mean & 19.3 & 18.6 & 20.1 & 24.6 & 16.6 & 36.7 & 5.8 & 13.2 & 8.3 \\
\hline & sd & 3.2 & 13.0 & 6.6 & 13.8 & 2.3 & 11.5 & 2.6 & 3.2 & 3.4 \\
\hline & & 0.11 & 0.13 & 0.16 & 0.18 & 0.08 & 0.19 & 0.11 & 0.27 & 0.11 \\
\hline \multicolumn{11}{|c|}{ \% zooplankton biomass } \\
\hline \multirow[t]{2}{*}{ Copepod } & mean & 85.5 & 81.2 & 68.8 & 65.7 & 62.9 & 64.2 & 69.0 & 59.5 & 63.8 \\
\hline & sd & 8.1 & 31.3 & 10.1 & 16.7 & 14.3 & 9.8 & 6.7 & 10.9 & 0.0 \\
\hline \multirow[t]{2}{*}{ Gelatinous } & mean & 1.3 & 1.8 & 4.8 & 7.0 & 14.1 & 14.3 & 7.3 & 4.6 & 0.8 \\
\hline & $s d$ & 0.5 & 0.7 & 1.7 & 2.1 & 3.2 & 2.9 & 0.2 & 0.1 & 0.7 \\
\hline \multirow[t]{2}{*}{ Other } & mean & 1.1 & 1.1 & 0.9 & 7.2 & 8.5 & 4.7 & 0.7 & 1.6 & 6.7 \\
\hline & $s d$ & 0.4 & 0.9 & 0.8 & 7.3 & 5.8 & 2.7 & 0.9 & 1.9 & 4.6 \\
\hline \multirow[t]{2}{*}{ meroplankton } & mean & 12.1 & 15.9 & 25.5 & 20.2 & 14.5 & 16.8 & 23.0 & 34.3 & 28.6 \\
\hline & $s d$ & 1.0 & 8.2 & 14.0 & 13.4 & 3.9 & 7.5 & 22.6 & 34.9 & 84.5 \\
\hline \multicolumn{11}{|c|}{ Zooplankton grazing pressure } \\
\hline \multirow[t]{2}{*}{$\mathrm{ZCD}\left(\mathrm{mg} \mathrm{m}^{-3} \mathrm{~d}^{-1}\right)$} & mean & 13.7 & 13.0 & 14.2 & 17.1 & 12.2 & 26.1 & 2.2 & 5.1 & 3.7 \\
\hline & $s d$ & 2.3 & 9.0 & 5.0 & 9.6 & 1.6 & 7.0 & 1.0 & 1.2 & 1.5 \\
\hline \multirow[t]{2}{*}{$\%$ phyto $d^{-1}$} & mean & 8.1 & 9.4 & 11.3 & 14.6 & 6.1 & 15.3 & 4.3 & 10.6 & 5.0 \\
\hline & $s d$ & 1.6 & 6.8 & 0.9 & 8.3 & 2.3 & 9.4 & 4.0 & 5.0 & 2.3 \\
\hline
\end{tabular}


Table 6. Mean ratio between flood and ebb periods for chlorophyll and particulate matter and for the abundances of total zooplankton and of zooplankton groups or taxa calculated for the integrated water column (Col.) and for the surface (Surf.) and bottom (Bot.) strata and for the biomass and grazing pressure of total zooplankton; T-tests between ebb and flood tide means reveal significantly different means with $\mathrm{p}<0.05(*)$. Ratio corresponding to significant ebb-flood differences are in red characters.

\begin{tabular}{|c|c|c|c|c|c|c|c|c|c|c|c|c|}
\hline & \multicolumn{3}{|c|}{ WHOLE DATA } & \multicolumn{3}{|c|}{ OCTOBER 6, 2016} & \multicolumn{3}{|c|}{ OCTOBER 10, 2016} & \multicolumn{3}{|c|}{ APRIL 13, 2016} \\
\hline & Col. & Bot. & Surf. & Col. & Bot. & Surf. & Col. & Bot. & Surf. & Col. & Bot. & Surf. \\
\hline Chlorophyll & 1.56 & nd & nd & 1.07 & nd & 0.72 & 1.72 & nd & 1.56 & 0.67 & nd & nd \\
\hline SS & 0.82 & 0.75 & 0.88 & 0.78 & 0.82 & 0.75 & 0.93 & 0.86 & 1.01 & 0.72 & 0.59 & 0.88 \\
\hline POM & 0.86 & 0.72 & 1.02 & 0.78 & 0.56 & 1.02 & 1.00 & 0.92 & 1.08 & 0.80 & 0.67 & 0.96 \\
\hline \multicolumn{13}{|l|}{ Abundance (ind $\mathrm{m}^{-3}$ ) } \\
\hline Total Zooplankton & $2.22 *$ & $3.21 *$ & 1.07 & $2.02 *$ & 2.04 & 2.05 & $3.44 *$ & $8.59 *$ & 0.58 & $1.75 *$ & $2.80 *$ & 0.83 \\
\hline Copepods & $2.37 *$ & $3.37 *$ & 1.26 & $2.18 *$ & 2.09 & 2.46 & $3.30 *$ & $9.54 *$ & 0.60 & $1.98 *$ & $3.03 *$ & 0.99 \\
\hline Gelatinous & 1.66 & $2.40 *$ & 0.62 & 1.32 & 2.00 & 0.96 & $5.56 *$ & $10.45 *$ & 0.60 & 0.99 & 1.33 & 0.40 \\
\hline Other holoplankton & 2.33 & 2.93 & 1.52 & 1.78 & abs & 0.50 & 19.96 & 35.50 & 0.00 & 1.91 & 0.50 & 10.00 \\
\hline Meroplankton & 1.40 & $2.26 *$ & 0.65 & 1.47 & 1.64 & 1.01 & 2.59 & 4.87 & 0.48 & 0.96 & 1.78 & 0.46 \\
\hline Copepod nauplii & $1.99 *$ & $2.66 *$ & 0.87 & 1.91 & 2.40 & 1.63 & $5.04 *$ & $19.30 *$ & 0.61 & 1.17 & $1.49 *$ & 0.65 \\
\hline Copepodites & $1.91 *$ & 2.34 & 1.08 & $1.69 *$ & 1.53 & 1.83 & $3.42 *$ & $11.71 *$ & 0.54 & 1.33 & 1.52 & 0.86 \\
\hline Calanoids & $2.17 *$ & $3.59 *$ & 1.57 & 2.41 & $2.88 *$ & 2.91 & 1.98 & $3.47 *$ & 1.08 & 2.18 & 6.95 & 1.62 \\
\hline Cyclopids & $1.93 *$ & $2.88 *$ & 0.97 & $3.71 *$ & 3.46 & 4.03 & 1.43 & 3.65 & 0.13 & 1.64 & 2.04 & 0.86 \\
\hline Harpacticoids & $2.80 *$ & $3.12 *$ & 1.80 & 1.73 & 1.06 & 3.92 & 4.64 & 14.82 & 0.50 & $4.22 *$ & $7.23 *$ & 1.32 \\
\hline Other copepods & 1.28 & 3.22 & 0.38 & 2.01 & 1.50 & 4.00 & 1.12 & 9.00 & 0.00 & 0.97 & abs & 0.00 \\
\hline Acartia latisetosa & 1.94 & 3.70 & 2.34 & 1.28 & 2.10 & 1.29 & 6.75 & 8.75 & 6.08 & 2.63 & 30.56 & 3.50 \\
\hline Paracalanus parvus & 1.20 & 1.95 & 0.66 & 2.40 & 1.92 & 3.05 & 1.46 & $3.82 *$ & 0.46 & 0.34 & 1.00 & 0.00 \\
\hline Oithona nana & $2.14 *$ & $3.12 *$ & 0.99 & $4.28 *$ & 3.82 & 4.86 & 1.76 & $4.58 *$ & 0.10 & 1.65 & 2.00 & 0.88 \\
\hline Euterpina acutifrons & $4.54 *$ & $4.12 *$ & 2.87 & $3.21 *$ & 2.09 & $6.71 *$ & 16.67 & 26.71 & 2.60 & $4.55 *$ & $6.91 *$ & 1.55 \\
\hline Oikeuplora dioica & 1.56 & $2.02 *$ & 0.70 & 1.26 & 1.85 & 0.96 & $5.60 *$ & $10.29 *$ & 0.61 & 1.00 & 1.17 & 0.67 \\
\hline Cirriped larvae & 1.32 & 2.36 & 0.59 & 6.35 & 2.50 & abs & 1.63 & 1.29 & 0.00 & 0.29 & abs & 0.14 \\
\hline Bivalve larvae & 1.01 & 1.14 & 0.57 & 0.94 & 0.27 & 1.25 & 2.05 & 3.39 & 0.35 & 0.50 & 0.67 & 0.40 \\
\hline Gastropod larvae & 1.16 & 2.31 & 0.50 & 0.73 & 1.47 & 0.51 & 5.56 & 21.64 & 0.78 & 0.97 & 1.70 & 0.41 \\
\hline Polychaete larvae & $2.45 *$ & 2.33 & 1.35 & 6.00 & 1.00 & abs & $4.25 *$ & $13.00 *$ & 1.33 & 1.36 & 2.09 & 0.21 \\
\hline Zoopl. biomass $\left(\mathrm{mg} \mathrm{C} \mathrm{m}^{-3}\right.$ ) & $2.41 *$ & nd & nd & $2.00 *$ & nd & nd & $3.49 *$ & nd & nd & $1.82 *$ & nd & nd \\
\hline \multicolumn{13}{|c|}{ Zooplankton grazing pressure : } \\
\hline ZCD mg C $\mathrm{m}^{-3} \mathrm{~d}^{-1}$ ) & $2.76 *$ & nd & nd & $2.10 *$ & nd & nd & $4.10 *$ & nd & nd & $2.06 *$ & nd & nd \\
\hline$\%$ phytoplankton stock $\mathrm{d}^{-1}$ & $2.49 *$ & nd & nd & $2.11 *$ & nd & nd & $2.37 *$ & nd & nd & $3.09 *$ & nd & nd \\
\hline
\end{tabular}


Table 7. Comparison of total zooplankton abundance in different lagoon and coastal ecosystems of the Mediterranean Sea.

\begin{tabular}{|c|c|c|c|c|c|c|c|c|}
\hline \multirow[t]{2}{*}{ Site } & \multirow[t]{2}{*}{ Sampling period } & \multirow[t]{2}{*}{ Net mesh size } & \multirow[t]{2}{*}{ Depth } & \multirow[t]{2}{*}{ Salinity } & \multicolumn{2}{|c|}{ Abundance (ind $m-3$ ) } & \multirow[t]{2}{*}{ Dominant taxa } & \multirow[t]{2}{*}{ Reference } \\
\hline & & & & & mean & range & & \\
\hline Bizerte lagoon, Tunisia & Nov 2012 - Augt 2014 & $200 \mu \mathrm{m}$ & $7-8 m$ & 34-38 & 2978 & $(400-11000)$ & Calanoid copepods & Gueroun et al.,2020 \\
\hline Tunis lagoon, Tunisia & March2001 - Sept 2002 & $70 \mu \mathrm{m}$ & $1,5 \mathrm{~m}$ & $35-44$ & 9300 & $(200-76000)$ & $\begin{array}{l}\text { Oithona nana, Acartia clausi, Euterpina } \\
\text { acutifrons, Centropages kroyeri, } \\
\text { Stephos marsalensis, Oithona } \\
\text { helgolandica, Acartia discaudata, }\end{array}$ & Annabi Trabelsi et al., 2005 \\
\hline Tunis Bay, Tunisia & Dec 1993 - Nov 1995 & $55 \mu m-300 \mu m$ & 3-30m & $37-38$ & 3962 & $(2500-20000)$ & $\begin{array}{l}\text { O. nana, } O \text {. helgolandica, } \text { A. clausi, } \\
\text { Euterpina acutifrons, Centropages kroyeri }\end{array}$ & Daly Yahia et al., 2004 (from their Fig. 5) \\
\hline Gulf of Tunis, Tunisia & Dec 2007- Apr 2008 & $220 \mu \mathrm{m}$ & $10-100 m$ & & 870 & $(350-2600)$ & $\begin{array}{l}\text { Paracalanus parvus, Clausocalanus lividus, } \\
\text { Centropages kroyeri and Acartia clausi }\end{array}$ & BenLamine et al.,2015 (from their Table 1a) \\
\hline Ghar EIMeh lagoon, Tunisia & Feb 2011 - Jan 2012 & $100 \mu m$ & $1-2 m$ & $27-51$ & & (95000-390000) & $\begin{array}{l}\text { O. nana, A. clausi, P. parvus, bivalve } \\
\text { larvae, gastropod larvae, polychaet larvae }\end{array}$ & Ziadi et al., 2015 \\
\hline \multirow{6}{*}{ Boughrara lagoon, Tunisia } & oct-17 & $60 \mu m-200 \mu m$ & $8-10 m$ & 45-46 & 24600 & $(9600-50000)$ & $\begin{array}{l}\text { Oithona nana, Acartia latisetosa, } \\
\text { Euterpina acutifrons, Paracalanus parvus, } \\
\text { gasteropod, bivalve, polychaete larvae }\end{array}$ & this study \\
\hline & Apr 2017 & $60 \mu \mathrm{m}-200 \mu \mathrm{m}$ & 8-10m & $42-43$ & 7800 & $(1400-11300)$ & & \\
\hline & Summer 1992 & $55 \mu \mathrm{m}$ & $14 m$ & \multirow{4}{*}{$40-51$} & 44845 & & \multirow{4}{*}{$\begin{array}{l}\text { O. nana, Paracalanus parvus, Euterpina } \\
\text { acutifrons, Centropages kroyeri, A. clausi, } \\
\text { A. latisetosa, Clytemnestra rostrata, }\end{array}$} & \multirow{4}{*}{ Daly Yahia and BenRomdhane, 1994} \\
\hline & Automn 1992 & $55 \mu \mathrm{m}$ & $14 m$ & & 46552 & & & \\
\hline & Winter 1992-1993 & $55 \mu \mathrm{m}$ & $14 m$ & & 27224 & & & \\
\hline & Spring 1994 & $55 \mu \mathrm{m}$ & $14 m$ & & 28089 & & & \\
\hline $\begin{array}{l}\text { Gulf of Gabés coastal (South), } \\
\text { Tunisia }\end{array}$ & October2017 & $60 \mu m-200 \mu m$ & 8-12m & $40-41$ & 9974 & $(3600-20300)$ & \multicolumn{2}{|c|}{$\begin{array}{l}\text { Oithona nana, Acartia latisetosa, } \\
\text { Euterpina acutifrons, Paracalanus parvus, this study } \\
\text { gasteropod, bivalve, polychaete larvae }\end{array}$} \\
\hline $\begin{array}{l}\text { Gulf of Gabés coastal (North), } \\
\text { Tunisia }\end{array}$ & March 2013 & $100 \mu \mathrm{m}$ & $0.5-4 m$ & $37-40$ & 10250 & $(1400-48000)$ & $\begin{array}{l}\text { Oithona nana, Paracalanus parvus, Tisbe } \\
\text { battagliai, Euterpina acutifrons, Oithona } \\
\text { plumifera, } \\
\text { Calanus helgolandicus Acartia latisetosa }\end{array}$ & Drira et al., 2017 \\
\hline \multirow[b]{2}{*}{ Gulf of Gabès open sea, Tunisia } & \multirow[b]{2}{*}{ July 2005} & \multirow[b]{2}{*}{$100 \mu \mathrm{m}$} & $<50 m$ & $37-38$ & 7410 & $(1460-43000)$ & \multirow{2}{*}{$\begin{array}{l}\text { Acartia clausi, Oithona nana, Temora } \\
\text { longicornis, Oithona helgolandica, } \\
\text { Paracartia grani }\end{array}$} & \multirow[t]{2}{*}{ Drira et al., 2010} \\
\hline & & & $>50 m$ & $37-38$ & 1372 & $(200-5500)$ & & \\
\hline Bardawillagoon, Egypt & October 2002 & $20 \mu \mathrm{m}$ & $0.5-2 m$ & $40-63$ & 122000 & $(66000-216000)$ & $\begin{array}{l}\text { O. nana, Lucicutia flavicornis, Centropages } \\
\text { calaninus, Clausocalanus furcatus, } \\
\text { molluscs larvae }\end{array}$ & Mageed, 2006 \\
\hline \multirow[t]{2}{*}{ Thau Lagoon, South France } & March 1982-March 1983 & $150 \mu \mathrm{m}$ & $1-11 \mathrm{~m}$ & $35-40$ & & $(11-20000)$ & $\begin{array}{l}\text { Acartia clausi, A. discaudata, A. bifilosa, A. } \\
\text { latisetosa, Oithona nana, Oithona } \\
\text { helgolandica, Euterpina acutifrons, } \\
\text { Paracalanus parvus, Centropages kroyeri }\end{array}$ & Lam Hoai, 1985 \\
\hline & 2010-2011 & $80 \mu \mathrm{m}$ & $4.8 m$ & $35-40$ & & $(99-55826)$ & & Marques et al., 2015 \\
\hline Berre Lagoon, France & 2008-2010 & $80 \mu m-700 \mu m$ & $1-9 m$ & nov-36 & 42000 & $(8000-280000)$ & $\begin{array}{l}\text { Acartia clausi, A. tonsa, Oithona nana, } \\
\text { Centropages typicus, Paracalanus parvus, } \\
\text { cirriped larvae }\end{array}$ & Delpy et al., 2012 \\
\hline $\begin{array}{l}\text { Sacca Del Canarin, Po Delta, } \\
\text { Italy }\end{array}$ & Aug 1981 & $90 \mu \mathrm{m}$ & $1 \mathrm{~m}$ & $15-35$ & 92000 & & $\begin{array}{l}\text { Acartia clausi, Paracalanus parvus, } \\
\text { Oithona nana, Euterpina acutifrons }\end{array}$ & Ferrari et al., 1985 \\
\hline $\begin{array}{l}\text { Venice Lagoon (central part), } \\
\text { Italy }\end{array}$ & 1995 & $80 \mu \mathrm{m}$ & $0.8-1.5 m$ & $5-37$ & 18302,5 & $(2800-38000)$ & $\begin{array}{l}\text { Oithona nana, Oncaea waldemari, Bivalvia } \\
\text { larvae, Acartia tonsa, Euterpina } \\
\text { acutifrons, Paracalanus parvus }\end{array}$ & Riccardi, 2010 \\
\hline
\end{tabular}




\section{Supplementary material}

Table S1. Importance value indexes (IVI) for the taxa inventoried during the two COZOMED campaigns in October 2016 and April 2017 in the three zones and at st 8. 


\begin{tabular}{|c|c|c|c|c|c|c|c|c|c|c|}
\hline & \multirow[b]{3}{*}{ Abrev. } & \multirow{2}{*}{\multicolumn{5}{|c|}{ October 2016}} & \multirow{2}{*}{\multicolumn{4}{|c|}{ April 2017}} \\
\hline & & & & & & & & & & \\
\hline & & Sea & Trans. & Lag. & Station8 & Total & Sea & Trans. & Lag. & Total \\
\hline Number of taxa & & 66 & 81 & 67 & 21 & 93 & 53 & 57 & 39 & 68 \\
\hline \multicolumn{11}{|l|}{ COPEPODA CALANOIDA } \\
\hline Acartia clausi & A. clausi & & & & & & 33.4 & 103.2 & 34.0 & 73.4 \\
\hline Acartia latisetosa & A. latis. & 83.3 & 103.8 & 101.5 & 272.3 & 104.8 & 124.2 & 118.8 & 122.4 & 115.4 \\
\hline Acartia sp. & A. sp1. & & & & & & 34.1 & 64.4 & 68.2 & 58.7 \\
\hline Aegistus spp. & Ae. Spp. & 33.3 & 38.9 & 57.2 & 101.0 & 43.8 & 105.4 & 88.3 & 67.5 & 87.5 \\
\hline Other calanoids & Oth. Cal. & 83.3 & 27.8 & 14.3 & & 34.4 & & 12.5 & 33.5 & 14.3 \\
\hline Calanopia minor & Cp. minor & & 5.6 & & & 3.1 & & & & \\
\hline Calanopia sp. & Cp. sp1 & & & & & & & 12.5 & & 7.2 \\
\hline Calanus helgolandicus & Cal. Helgo. & & 27.8 & 14.3 & & 18.8 & 70.6 & 25.4 & & 29.7 \\
\hline Calanus spp. & Cal. Spp. & 100.0 & 101.9 & 100.8 & 100.6 & 103.0 & 69.8 & 62.6 & 67.3 & 65.2 \\
\hline Canuella sp. & Canuella.sp. & & 5.6 & & & 3.1 & & & & \\
\hline Centropages ponticus & Cen. Pont. & 33.3 & 72.6 & 101.5 & & 69.3 & 101.6 & 106.7 & 112.9 & 107.0 \\
\hline Centropages spp. & Cen. Spp. & 33.3 & 50.2 & 85.9 & & 53.3 & 100.8 & 75.9 & 107.4 & 88.0 \\
\hline Centropages typicus & Cen. typicus & 16.7 & 55.7 & 14.3 & & 37.6 & & & & \\
\hline Clausocalanus sp. & Claus. sp. & 102.1 & 109.4 & 105.5 & & 120.5 & 33.4 & 25.1 & & 21.5 \\
\hline Ctenocalanus spp. & Cten. spp. & & & & & & 33.4 & 87.6 & & 57.2 \\
\hline Heterhabdus sp. & Heter. sp. & & & & & & 100.8 & 12.5 & & 28.7 \\
\hline Mecynocera & Mecyno. & 83.3 & 96.0 & 72.3 & & 86.2 & 33.4 & & & 7.1 \\
\hline Metridia Maetidea sp2. & Metridia & 16.7 & 55.6 & & & 34.4 & & & & \\
\hline Nannocalanus minor & N. minor & 16.7 & & & & 3.1 & & & & \\
\hline Paracalanus indicus & P. indicus & 50.0 & 61.5 & 71.6 & & 59.7 & 100.5 & 25.0 & 33.3 & 43.0 \\
\hline Paracalanus parvus & P. parvus & 100.0 & 106.6 & 102.8 & & 103.1 & 107.5 & 100.7 & 100.2 & 102.0 \\
\hline Paracalanus sp. & P.sp. & 16.7 & 61.4 & 71.5 & & 53.3 & & & & \\
\hline Phaenna sp. & Phae.sp. & 16.7 & & & & 3.1 & & & & \\
\hline Phaeanna spinifera & Phae. Spini. & 102.1 & 89.3 & 85.9 & 102.8 & 99.8 & 67.2 & 12.5 & & 21.5 \\
\hline Platycopia pygmea & P. pygmea. & & 66.9 & 28.6 & & 43.9 & & & & \\
\hline Pontella mediterranea & Pont. Med & 83.3 & 61.5 & & & 50.4 & & & & \\
\hline Pseudodiaptomus sp. & Pseudo. sp. & & & & & & 33.4 & & & 7.1 \\
\hline Rhincalanus sp. & Rhin. sp. & & & & & & 33.4 & & & 7.2 \\
\hline Scolecitrix sp. & Scolx. sp. & & & & & & 100.5 & & & 21.5 \\
\hline Temora stylifera & T. stylifera & & & & & & 100.4 & & & 21.5 \\
\hline Tortanus sp. & Tor. Sp. & & & & & & 67.2 & 75.7 & 67.4 & 72.1 \\
\hline \multicolumn{11}{|l|}{ COPEPODA CYCLOPIDA } \\
\hline Farranula spp. & F. spp. & & & & & & 100.3 & 25.0 & & 35.8 \\
\hline Lubbokia acuelata & L. acuelata & 16.7 & & & & 3.1 & & & & \\
\hline Oithona helgolandica & O. helgo & 66.7 & 95.7 & 100.9 & & 88.5 & & & & \\
\hline Oithona nana & O. nana & 102.1 & 118.4 & 124.5 & 101.3 & 167.4 & 111.8 & 115.5 & 108.5 & 112.7 \\
\hline Oithona plumifera & O. plumif & & 5.6 & 14.3 & & 6.3 & 67.3 & 25.3 & & 28.9 \\
\hline Oithona similis & O. similis & 100.0 & 103.1 & 102.5 & & 99.4 & 66.7 & 25.2 & 33.4 & 35.9 \\
\hline Oithona simplex & O. simplex & & & & & & & 63.4 & 33.3 & 43.4 \\
\hline Oithona spp. & O. spp. & 16.7 & 16.7 & & & 12.5 & 33.4 & 25.2 & 67.5 & 36.0 \\
\hline Oncaea borealis & Onc. borealis & & 5.6 & & & 3.1 & & & & \\
\hline Oncaea mediterranea & Onc. Med & & 33.4 & 14.3 & & 21.9 & & & & \\
\hline Oncaea minuta & Onc. minuta & 16.7 & & & & 3.1 & & & & \\
\hline Oncaea spp. & Onc. spp. & & 11.1 & & & 6.3 & 100.2 & & 33.4 & 28.6 \\
\hline Sapphirina sp. & Sap. sp & & 11.2 & & & 6.3 & & & & \\
\hline Saphirella sp. & Sapl. sp. & 50.0 & 28.0 & 14.4 & & 28.4 & & & & \\
\hline \multicolumn{11}{|c|}{ COPEPODA HARPACTICOIDA } \\
\hline Clymtenestra scutellata & Clyt. Scut & 16.7 & & 28.6 & 100.1 & 12.5 & 33.4 & 50.0 & 33.5 & 42.9 \\
\hline Clytemnestra sp. & Clyt. Sp. & & & & & & & 25.1 & & 14.4 \\
\hline Euterpina acutifrons & E. acuti & 100.0 & 106.7 & 100.9 & 101.3 & 105.1 & 102.6 & 126.1 & 103.3 & 114.6 \\
\hline Euterpina sp. & E.sp. & 16.7 & 11.1 & & & 9.4 & 33.4 & & & 7.1 \\
\hline Harpact sp. & H.sp. & & 33.4 & 71.5 & 100.7 & 37.5 & & & & \\
\hline Harpacticoides spp. & H. spp. & 100.0 & 106.2 & 107.5 & 107.9 & 111.6 & 102.7 & 102.0 & 35.1 & 87.8 \\
\hline Lubbockia sp. & L. sp & 83.3 & 103.9 & 90.2 & & 94.2 & & & & \\
\hline Macrosetella spp. & M. spp & 16.7 & 33.5 & 28.7 & & 28.2 & & & & \\
\hline Metis ignea & M. ignea & & 33.4 & 14.3 & & 21.9 & & & & \\
\hline Microsetella norvegia & M. norvegia & 16.7 & 61.3 & 85.9 & 101.3 & 59.6 & & & & \\
\hline Microsetella rosea & M. rosea & & 5.6 & & & 3.1 & & & & \\
\hline Microsetella sp. & M. sp. & & & & & & & 50.0 & 33.4 & 35.8 \\
\hline Tegastidae & T. Tegastidae & & 11.1 & & & 6.3 & & & & \\
\hline Tisbe & T. Tisbe & 16.7 & 44.7 & 28.6 & & 34.5 & & & & \\
\hline \multicolumn{11}{|l|}{ OTHER COPEPODA } \\
\hline Cymbasoma rigidum(Mon & I Cym. rigid. & & 11.1 & & & 6.3 & & & & \\
\hline Monstrilla clavata & M. clavata & & 16.7 & 28.6 & & 15.6 & & & & \\
\hline Monstrillia grandis & M. grandis & & & & & & 66.7 & 25.0 & & 28.6 \\
\hline Caligidae & C. Caligidae & & & & & & & 12.5 & 33.4 & 14.3 \\
\hline Other & Other & 50.0 & 90.0 & 100.5 & & 82.1 & & & & \\
\hline
\end{tabular}


Table S1. (follow)

\begin{tabular}{|c|c|c|c|c|c|c|c|c|c|c|}
\hline & \multirow[b]{2}{*}{ Abrev. } & \multicolumn{5}{|c|}{ October 2016} & \multicolumn{4}{|c|}{ April 2017} \\
\hline & & Sea & Trans. & Lag. & Station8 & Total & Sea & Trans. & Lag. & Total \\
\hline \multicolumn{11}{|l|}{ CRUSTACEAN } \\
\hline Amphipode spp. & A. spp. & & 66.7 & 14.3 & & 40.6 & 33.4 & 50.0 & 66.8 & 50.1 \\
\hline Cladocera sp. & Clad.sp. & 66.7 & 27.8 & 14.3 & & 31.3 & & & & \\
\hline Evadne sp. & E.sp. & & 16.7 & 86.0 & 100.3 & 31.3 & & & & \\
\hline Pseudoevadne tergestina & P. tergestina & 66.7 & 55.6 & 86.2 & & 62.7 & 0.0 & 12.5 & 0.0 & 7.2 \\
\hline Podon spp. & P. spp. & 16.7 & 27.8 & 71.6 & & 34.4 & 33.4 & 75.3 & 101.7 & 72.0 \\
\hline Conchoecia obstustata & Con. obstustata & & 55.9 & 100.9 & & 53.5 & & & & \\
\hline Cypridina globosa & Cyp. globosa & & 5.6 & & & 3.1 & & & & \\
\hline Cypridina mediterranea & Cyp. mediterranea & & 5.6 & & & 3.1 & & & & \\
\hline Cytheridea sp. & Cyt. sp. & & 11.4 & & & 6.4 & & & & \\
\hline Ostracode spp. & O. spp. & 33.3 & 44.5 & 42.9 & 100.1 & 43.8 & 33.6 & 87.8 & 66.7 & 71.6 \\
\hline Crustacean spp. & C. spp. & & 5.6 & & & 3.1 & & & & \\
\hline Mysidacea & M. & 83.3 & 44.7 & 71.5 & & 56.4 & & 25.1 & & 14.3 \\
\hline \multicolumn{11}{|l|}{ GELATINOUS } \\
\hline Appendicular & App. & 16.7 & 11.1 & 14.3 & & 12.5 & 34.2 & 12.6 & & 14.5 \\
\hline Oikeuplora dioica & Oik. dioica & 83.3 & 108.7 & 121.5 & 101.3 & 121.1 & 103.7 & 102.6 & 101.5 & 102.6 \\
\hline Oikopleura spp. & Oik. Spp. & & & 85.7 & & 18.8 & 101.2 & 87.9 & 66.9 & 86.3 \\
\hline Chaetognathes spp. & Chae.spp. & 33.3 & 27.8 & 57.2 & & 34.4 & & & & \\
\hline Sagitta lyra gazellae & S. gazellae & 16.7 & & 71.6 & & 18.8 & & & & \\
\hline Sagitta setosa & S. setosa & 100.0 & 66.9 & 72.0 & & 72.1 & 67.3 & 100.1 & 33.3 & 78.8 \\
\hline Sagitta sp. & S. sp. & 33.3 & 44.5 & 28.6 & & 37.5 & & & & \\
\hline Anthomedusa & A. spp. & & & & & & 33.4 & & & 7.1 \\
\hline Jellyfish medusa & E. méduse & & 66.8 & 57.2 & 100.1 & 53.2 & & & & \\
\hline Clytia roliformis & Abrev. & & & 14.3 & & 3.1 & & & & \\
\hline Leptomedusa spp. & L. spp. & 16.7 & 5.6 & & & 6.3 & & 12.5 & & 7.2 \\
\hline Obelia sp. & O.sp. & 16.7 & 22.2 & 71.5 & & 31.3 & 100.5 & 12.5 & & 28.7 \\
\hline Muggia kochi & M. kochi & & & & & & 66.8 & & & 14.3 \\
\hline Siphonophore spp. & S. spp. & & & & & & 67.0 & & & 14.4 \\
\hline \multicolumn{11}{|l|}{ MEROPLANKTON } \\
\hline Ascidea larvea & Asc. L. & & 61.4 & 85.8 & 100.1 & 56.4 & & 37.6 & 33.3 & 28.6 \\
\hline Balanus Nauplii & Balanus & 66.7 & 95.8 & 101.6 & 102.2 & 91.9 & 33.4 & 75.5 & 67.2 & 64.7 \\
\hline Chthamalus Nauplii & Chthamalus & 100.0 & 103.9 & 102.5 & 101.3 & 102.9 & & 62.9 & 67.5 & 50.4 \\
\hline Bivalva larvae & Biv. L. & 100.0 & 106.7 & 112.4 & 102.6 & 107.1 & 66.8 & 88.1 & 100.4 & 86.2 \\
\hline Crustacean larvea & Crust. L. & 100.0 & 89.0 & 86.4 & 100.8 & 90.9 & & 37.5 & & 21.4 \\
\hline Lucifer & Leu. & 100.0 & 44.5 & 14.3 & & 47.2 & 33.4 & & & 7.1 \\
\hline Decapods larvae & decap. L. & 100.0 & 44.6 & 71.5 & & 60.2 & & 12.5 & & 7.2 \\
\hline zoe crab larvea & Crab L. & 100.0 & 72.7 & 57.2 & & 72.3 & 100.6 & 75.1 & 66.8 & 78.8 \\
\hline blue crab zoe larvea & Blue crab L. & & & & & & 66.8 & 62.5 & 33.4 & 57.2 \\
\hline Palaemon elegans Larvea & P. elegans & 83.3 & 61.1 & 57.2 & & 62.5 & & & & \\
\hline Sicyonia carinata protozoe & Sic. Prot. & 83.3 & 16.7 & & & 25.0 & & & & \\
\hline Crustacean zoe & Z. crus. & 50.0 & & & & 9.4 & & & & \\
\hline Nauplii sp. & N. sp. & 33.3 & & 14.3 & & 9.4 & & & & \\
\hline Gastropod larvae & Gastero. L. & 100.1 & 108.7 & 112.7 & 101.3 & 114.1 & 141.7 & 119.0 & 157.9 & 125.2 \\
\hline Spider & Spider & & 16.7 & 28.6 & & 15.6 & & & & \\
\hline Actinotroc Larvae & Actino. $L$. & & & & & & & 12.6 & 33.4 & 14.4 \\
\hline Argule & Arg. & & & & & & & 25.0 & & 14.3 \\
\hline ND larvae & Larve ND & 33.3 & 61.4 & 85.8 & 100.4 & 62.7 & 33.4 & 37.5 & 33.3 & 35.7 \\
\hline Echinoderm larvae & Echino. L. & 16.7 & & & & 3.1 & & & & \\
\hline Mollusc larvea & Mollusc L. & 16.7 & 5.6 & & & 6.3 & & & & \\
\hline Fish larvae & F.L. & 16.7 & 33.4 & 42.9 & & 31.3 & 33.4 & 87.5 & & 57.2 \\
\hline Fish eggs & F.eg. & 83.3 & 22.3 & 72.0 & & 44.0 & 67.2 & 62.7 & 67.2 & 64.6 \\
\hline Diverse eggs & Div. eg & 100.0 & 95.0 & 101.3 & & 94.8 & 109.8 & 92.3 & 103.1 & 98.4 \\
\hline Polychet annelids larvae & Polych. L. & 100.0 & 83.9 & 102.1 & & 88.7 & 102.8 & 102.6 & 103.6 & 102.9 \\
\hline Polychet annelids eggs & Polych. Eg. & 33.3 & & & & 6.4 & & & & \\
\hline
\end{tabular}

